Article

\title{
Synthesis and Biological Evaluation of 3-Substituted-indolin-2- one Derivatives Containing Chloropyrrole Moieties
}

\author{
Yun-Zhou Jin ${ }^{1}$, Da-Xu Fu ${ }^{1}$, Nan Ma ${ }^{1}$, Zhan-Cheng Li ${ }^{1}$, Quan-Hai Liu ${ }^{2}$, Lin Xiao ${ }^{2}$ and \\ Rong-Hua Zhang ${ }^{1, *}$ \\ 1 Department of Chemistry, Tongji University, Shanghai, 200092, China \\ 2 Department of Pharmacology, Shanghai Institute of Pharmaceutical Industry, Shanghai, 200434, \\ China \\ * Author to whom correspondence should be addressed; E-Mail: tj_zrh@163.com; \\ Tel.: +86-021-65988570-8542.
}

Received: 10 October2011; in revised form: 3 November 2011 / Accepted: 3 November 2011 / Published: 8 November 2011

\begin{abstract}
Eighteen novel 3-substituted-indolin-2-ones containing chloropyrroles were synthesized and their biological activities were evaluated. The presence of a chlorine atom on the pyrrole ring was crucial to reduce cardiotoxicity. The presence of a 2-(ethylamino)ethylcarbamoyl group as a substituent at the C-4' position of the pyrrole enhanced the antitumor activities notably. $\mathrm{IC}_{50}$ values as low as $0.32,0.67,1.19$ and $1.22 \mu \mathrm{M}$ were achieved against non-small cell lung cancer (A549), oral epithelial (KB), melanoma (K111) and large cell lung cancer cell lines (NCI-H460), respectively.
\end{abstract}

Keywords: antitumor activities; indolin-2-one; chloropyrrole; synthesis

\section{Introduction}

Angiogenesis, an important physiological process of new capillary blood vessel formation, is essential for the survival, growth and metastasis of tumors [1,2]. Vascular endothelial growth factor (VEGF), platelet-derived growth factor (PDGF), fibroblast growth factor (FGF) and their receptor tyrosine kinases (RTKs) play key roles in angiogenesis and vascular maintenance via the autocrine and paracrine loops. Among these growth factors, by binding to its receptor VEGF is currently the most potent and clinically relevant angiogenic factor [3-5]. The vascular endothelial growth factor receptor (VEGFR) belongs to the RTKs superfamily and mainly comprises fms-like tyrosine kinase-1 (FLT-1, 
VEGFR1), kinase domain-containing receptor (KDR, VEGFR2) and fms-like tyrosine kinase-4 (FLT4, VEGFR3), which contribute to tumor progression via mediation of tumor angiogenesis and lymphangiogenesis [6,7]. Therefore, inhibition of the RTK pathway, which results in inhibition of tumor angiogenesis, has become an important strategy for discovering new antitumor drugs [8-11].

In recent years, indolin-2-one derivatives, especially those with heterocyclic methylene substituents attached to the C-3 position of the indolin-2-one ring, have been disclosed as potent inhibitors of RTK in vitro and demonstrated antiangiogenic properties in vivo. The (Z)-3-((3,5-dimethyl-1H-pyrrol-2yl)methylene) indolin-2-one structure is found in many antitumor drugs [12,13]. SU5416 (Figure 1) is the first selective KDR inhibitor in clinical trials. Its derivative SU11248 (sunitinib, Figure 1) was the first RTK oral inhibitor approved by the US Food and Drug Administration (FDA) for the treatment of advanced renal cell carcinoma and gastrointestinal stromal tumors [14-16]. In SU6668 (Figure 1) and sunitinib, 2-carboxyethyl and 2-diethylaminoethylcarbamoyl groups were introduced into the C-4' position of the pyrrole ring, respectively. Tang et al. reported that pyrrolo-fused-heterocycle-indolin-2-one analogues showed potent inhibition against VEGFR and good efficacies against HT-29 cell tumor xenografts in nude mice [17]. Khanwelkar et al. found that introduction of a ureido group into the C-6 position of 3-pyrrolemethylideneindolin-2-one enhances the potency of inhibition against VEGFR, PDGFR [18].

Figure 1. Structures of SU5416, SU6668 and sunitinib.

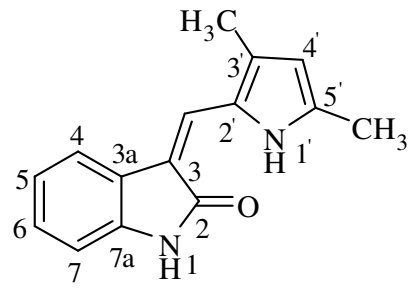

SU5416

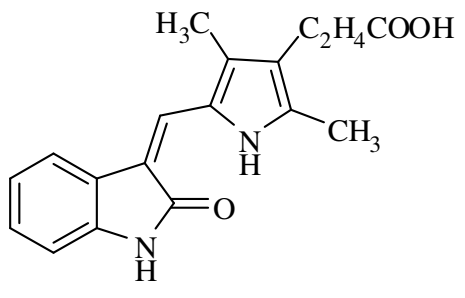

SU6668

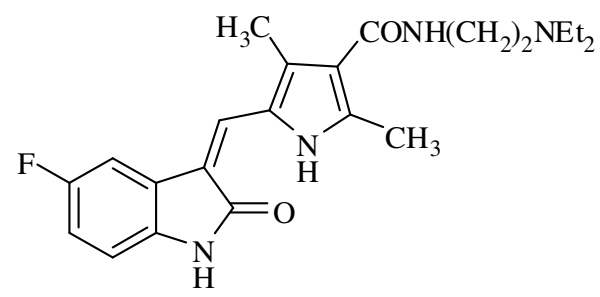

Sunitinib

The introduction of halogen atoms, mainly fluorine or chlorine, has been used as a tool to enhance the potency of many pharmaceutical lead compounds $[19,20]$. The presence of halogen atom changes the volumetric and conformational properties, as also increases membrane permeability leading to improved absorption [21]. The importance of chlorine atoms in drug design is well documented. Besides having a larger size than fluorine, chlorine is a moderate halogen bond acceptor. Compared with bromine and iodine, the chlorine-carbon bond is stable enough to be inserted into diverse heterocycles of pharmacological value. In some drugs, subunits bearing chlorine can be accommodated in hydrophobic pockets of the biological targets [22]. Hrib et al. reported that the introduction of chlorine into nemonapride constituted a ubiquitous function-determining domain, while the removal of the chlorine was deleterious to the selectivity among the dopaminergic receptors [23]. Among leishmanicidal $\mathrm{N}$-benzylcytisine derivatives, the chloro derivative demonstrated 10 -fold stronger inhibition ability than others [24]. On the aromatic ring of arvanil, the replacement of a 3-methoxy group with a chlorine atom increased the capability to inhibit FAAH [25].

In previous studies, we introduced halogen atoms onto the pyrrole rings attached to an indolin-2one framework and found that those with bromine atoms exhibited low antitumor activities, while 
those with chlorine atoms exhibited good antitumor activities and low cardiotoxicity. Crystallographic study of indolin-2-one with FGFR indicates that C-4' position on the pyrrole is positioned close to the opening of the binding pocket and could be exposed to solvents [26]. We envisioned that modification of the substituted indolin-2-ones by adjusting its hydrophilicity might further enhance their biological activities. Accordingly, we introduced different $\mathrm{N}$-substituents to a pyrrole-4'-formamide moiety attached to the $\mathrm{C}-3$ position of indolin-2-one. We were also curious about the effects of changing the substituents on the phenyl ring on the inhibitory activities. Herein, we wish to report the synthesis of eighteen novel substituted indolin-2-ones and the in vitro biological evaluation of their activity against four cancer cell lines (A549, KB, K111, NCI-H460), VEGFR2 and cardiotoxicity.

\section{Results and Discussion}

\subsection{Chemistry}

4-Chloro-5-formyl-2-methyl-1H-pyrrole-3-carboxylic acid (6) was prepared from vinyl acetate (1) in five steps (Scheme 1). Bromination of vinyl acetate (1), followed by reaction with ethyl acetoacetate, afforded pyrrole derivative $\mathbf{3}$. Treatment of $\mathbf{3}$ with freshly prepared Vilsmeier reagent gave aldehyde $\mathbf{4}$, which was chlorinated with sulfuryl chloride to afford $\mathbf{5}$. Compound $\mathbf{6}$ was obtained after hydrolysis of compound $\mathbf{5}$ with aqueous sodium hydroxide.

Scheme 1. Synthesis of 4-chloro-5-formyl-2-methyl-1H-pyrrole-3-carboxylic acid (6).
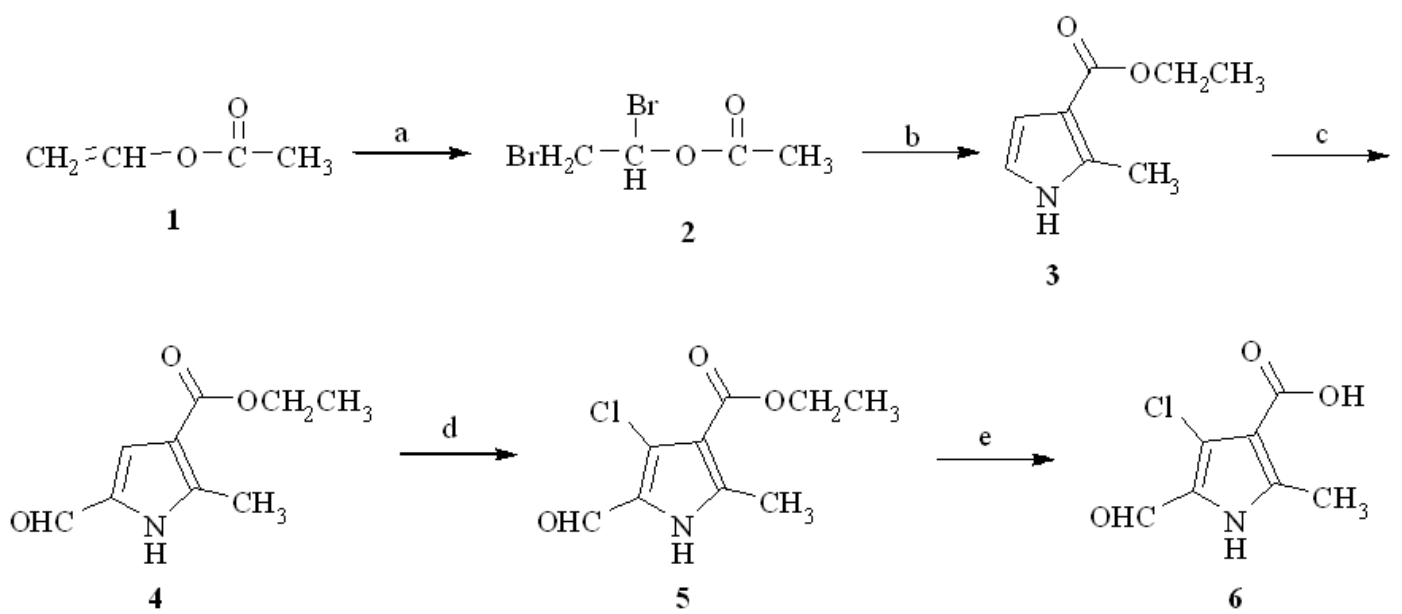

Reagents and conditions: (a) $\mathrm{Br}_{2} \mathrm{CCl}_{4}, 0-5{ }^{\circ} \mathrm{C}, 98 \%$; (b) ethyl acetoacetate, $17 \%$ ammonia, 0-10 ${ }^{\circ} \mathrm{C}, 50 \%$; (c) $\mathrm{POCl}_{3}$, DMF, 0-10 ${ }^{\circ} \mathrm{C}, 90 \%$; (d) $\mathrm{SO}_{2} \mathrm{Cl}_{2}, \mathrm{HOAc}, 0-5{ }^{\circ} \mathrm{C}, 44 \%$; (e) $10 \mathrm{~N}$ aq. $\mathrm{NaOH}, 80{ }^{\circ} \mathrm{C}, 75 \%$.

As shown in Scheme 2, the key intermediates 12a-d, analogues of $\mathbf{6}$, were prepared from ylide $\mathbf{7}$ in five steps. Wittig reaction of ylide 7 with aldehydes produced 3 -alkyl/H-acrylates 8a-c. Ethyl 4-alkyl/H-pyrrole-3-caboxylates 9a-c were prepared by the cyclization of 8a-c with tosylmethyl isocyanide (TosMIC). Formylation of 9a-c afforded 10a-c. Chlorination of substituted pyrrole 10-c and hydrolysis of the produced chloro-substituted esters 11a-d yielded the pyrrolecarboxylic acids 12a-d. 
Scheme 2. Synthesis of substituted 2-chloro-5-formyl-1H-pyrrole-3-carboxylic acids 12a-d.<smiles>[R]c1cn([R1]([H])([H])C)cc1C(=O)OCC</smiles><smiles>[R]c1c(C(=O)OCC)c[nH]c1C=O</smiles><smiles>CCOC(=O)c1c(Cl)[nH]c(C=O)c1C(=O)OCC</smiles>

Reagents and conditions: (a) aldehydes, benzene, reflux, 87-92\%; (b) TosMIC, Et 2 O/DMSO, NaH, r.t., 88-90\%; (c) $\mathrm{POCl}_{3}$, DMF, 0-10 ${ }^{\circ} \mathrm{C}, 85-93 \%$; (d) $\mathrm{SO}_{2} \mathrm{Cl}_{2}$, $\mathrm{HOAc}, 0-5{ }^{\circ} \mathrm{C}, 33-50 \%$; (e) $10 \mathrm{~N}$ aq. $\mathrm{NaOH}, 80^{\circ} \mathrm{C}, 75-92 \%$.

The synthetic route to target compounds 14a-r is shown in Scheme 3 (the substituents of these compounds are listed in Table 1). Compounds $\mathbf{6}$ and 12a-d were transformed into amides 13a-n by the reaction with different amines. Knoevenagel condensations of 13a-n with 5-substituted indolin-2-ones produced the target compounds $\mathbf{1 4 a - r}$.

Scheme 3. Synthesis of 3-substituted-indolin-2-one derivatives 14a-r.<smiles>[R]c1[nH]c(C=O)c([R])c1C(=O)O</smiles>

6: $\mathrm{R}^{2}=\mathrm{Cl} ; \mathrm{R}^{3}=\mathrm{CH}_{3}$ 12a-d: $\mathrm{R}^{2}=\mathrm{H}, \mathrm{CH}_{3}, \mathrm{C}_{2} \mathrm{H}_{5}, \mathrm{Cl} ; \mathrm{R}^{3}=\mathrm{Cl}$

Reagents and conditions: (a) amines, HOBt, EDCL, $\mathrm{Et}_{3} \mathrm{~N}$, DMF, r.t., 70-80\%; (b) 5-substituted indolin-2-ones, $\mathrm{EtOH}, \mathrm{Et}_{3} \mathrm{~N}, 40-55 \%$.

\subsection{Biological Evaluation}

The antitumor activities of 14a-r were evaluated in vitro on four tumor cell lines, including nonsmall cell lung cancer (A549), oral epithelial (KB), melanoma (K111) and large cell lung cancer cell lines (NCI-H460) by the MTT assay, and the results are summarized in Table 1. 
Table 1. Structures of compounds $\mathbf{1 4 a}-\mathbf{r}$ and their antitumor activities on four tumor cell lines.

\begin{tabular}{|c|c|c|c|c|c|c|c|c|}
\hline \multirow{2}{*}{ Compd. } & \multirow{2}{*}{$\mathbf{R}^{2}$} & \multirow{2}{*}{$\mathbf{R}^{3}$} & \multirow{2}{*}{$\mathbf{R}^{4}$} & \multirow{2}{*}{$\mathbf{R}^{5}$} & \multicolumn{4}{|c|}{$\mathrm{IC}_{50} \pm \mathrm{SD}(\mu \mathrm{M})$} \\
\hline & & & & & A549 & KB & K111 & NCI-H460 \\
\hline $14 \mathbf{a}$ & $\mathrm{Cl}$ & $\mathrm{CH}_{3}$ & $\mathrm{NHC}$ & $\mathrm{F}$ & $1.47 \pm 0.13$ & $52.91 \pm 7.93$ & $>100$ & $>100$ \\
\hline $14 b$ & $\mathrm{Cl}$ & $\mathrm{CH}_{3}$ & & $\mathrm{~F}$ & $>100$ & $>100$ & $>100$ & $>100$ \\
\hline $14 \mathrm{c}$ & $\mathrm{Cl}$ & $\mathrm{CH}_{3}$ & 11 & $\mathrm{~F}$ & $2.43 \pm 0.26$ & $1.35 \pm 0.12$ & $3.41 \pm 0.52$ & $1.41 \pm 0.17$ \\
\hline 14d & $\mathrm{Cl}$ & $\mathrm{CH}_{3}$ & $\mathrm{NH}\left(\mathrm{CH}_{2}\right)_{2} \mathrm{CH}_{3}$ & $\mathrm{~F}$ & $>100$ & $>100$ & $>100$ & $>100$ \\
\hline $14 e$ & $\mathrm{Cl}$ & $\mathrm{CH}_{3}$ & $\mathrm{NH}\left(\mathrm{CH}_{2}\right)_{3} \mathrm{~N}\left(\mathrm{CH}_{3}\right)_{2}$ & $\mathrm{~F}$ & $2.33 \pm 0.31$ & $2.88 \pm 0.33$ & $>100$ & $>100$ \\
\hline $14 f$ & $\mathrm{Cl}$ & $\mathrm{CH}_{3}$ & $\mathrm{NH}\left(\mathrm{CH}_{2}\right)_{2} \mathrm{~N}\left(\mathrm{CH}_{3}\right)_{2}$ & $\mathrm{~F}$ & $1.69 \pm 0.17$ & $1.56 \pm 0.08$ & $1.35 \pm 0.28$ & $1.67 \pm 0.18$ \\
\hline $14 g$ & $\mathrm{Cl}$ & $\mathrm{CH}_{3}$ & $\mathrm{NH}\left(\mathrm{CH}_{2}\right)_{2} \mathrm{NHC}_{2} \mathrm{H}_{5}$ & $\mathrm{~F}$ & $1.03 \pm 0.09$ & $0.67 \pm 0.08$ & $1.19 \pm 0.21$ & $1.41 \pm 0.09$ \\
\hline $14 \mathrm{~h}$ & $\mathrm{Cl}$ & $\mathrm{CH}_{3}$ & $\mathrm{NH}\left(\mathrm{CH}_{2}\right)_{2} \mathrm{~N}\left(\mathrm{C}_{2} \mathrm{H}_{5}\right)_{2}$ & $\mathrm{~F}$ & $1.87 \pm 0.26$ & $1.25 \pm 0.10$ & $1.79 \pm 0.12$ & $32.1 \pm 3.83$ \\
\hline $14 \mathbf{i}$ & $\mathrm{Cl}$ & $\mathrm{CH}_{3}$ & $\mathrm{NH}\left(\mathrm{CH}_{2}\right)_{2} \mathrm{~N}\left(\mathrm{C}_{2} \mathrm{H}_{5}\right)_{2}$ & $\mathrm{Cl}$ & $0.32 \pm 0.03$ & $1.15 \pm 0.20$ & $>100$ & $>100$ \\
\hline $14 \mathbf{j}$ & $\mathrm{Cl}$ & $\mathrm{CH}_{3}$ & $\mathrm{NH}\left(\mathrm{CH}_{2}\right)_{2} \mathrm{~N}\left(\mathrm{C}_{2} \mathrm{H}_{5}\right)_{2}$ & $\mathrm{Br}$ & $>100$ & $34.21 \pm 2.96$ & $>100$ & $>100$ \\
\hline $14 k$ & $\mathrm{Cl}$ & $\mathrm{CH}_{3}$ & $\mathrm{NH}\left(\mathrm{CH}_{2}\right)_{2} \mathrm{~N}\left(\mathrm{C}_{2} \mathrm{H}_{5}\right)_{2}$ & $\mathrm{H}$ & $>100$ & $5.09 \pm 1.01$ & $>100$ & $>100$ \\
\hline 141 & $\mathrm{Cl}$ & $\mathrm{CH}_{3}$ & $\mathrm{NH}\left(\mathrm{CH}_{2}\right)_{2} \mathrm{~N}\left(\mathrm{C}_{2} \mathrm{H}_{5}\right)_{2}$ & $\mathrm{CH}_{3}$ & $>100$ & $64.42 \pm 7.51$ & $>100$ & $>100$ \\
\hline $14 \mathrm{~m}$ & $\mathrm{Cl}$ & $\mathrm{Cl}$ & $\mathrm{NH}\left(\mathrm{CH}_{2}\right)_{2} \mathrm{~N}\left(\mathrm{C}_{2} \mathrm{H}_{5}\right)_{2}$ & $\mathrm{~F}$ & $>100$ & $>100$ & $>100$ & $>100$ \\
\hline $14 n$ & $\mathrm{H}$ & $\mathrm{Cl}$ & $\mathrm{NH}\left(\mathrm{CH}_{2}\right)_{2} \mathrm{~N}\left(\mathrm{C}_{2} \mathrm{H}_{5}\right)_{2}$ & $\mathrm{~F}$ & $3.37 \pm 0.27$ & $4.23 \pm 0.65$ & $>100$ & $>100$ \\
\hline 140 & $\mathrm{CH}_{3}$ & $\mathrm{Cl}$ & $\mathrm{NH}\left(\mathrm{CH}_{2}\right)_{2} \mathrm{~N}\left(\mathrm{C}_{2} \mathrm{H}_{5}\right)_{2}$ & $\mathrm{~F}$ & $2.14 \pm 0.26$ & $1.51 \pm 0.11$ & $>100$ & $>100$ \\
\hline $14 p$ & $\mathrm{CH}_{3}$ & $\mathrm{Cl}$ & $\mathrm{NH}\left(\mathrm{CH}_{2}\right)_{2} \mathrm{NHC}_{2} \mathrm{H}_{5}$ & $\mathrm{~F}$ & $1.41 \pm 0.09$ & $0.69 \pm 0.07$ & $1.24 \pm 0.16$ & $1.66 \pm 0.23$ \\
\hline $14 q$ & $\mathrm{C}_{2} \mathrm{H}_{5}$ & $\mathrm{Cl}$ & $\mathrm{NH}\left(\mathrm{CH}_{2}\right)_{2} \mathrm{~N}\left(\mathrm{C}_{2} \mathrm{H}_{5}\right)_{2}$ & $\mathrm{~F}$ & $16.71 \pm 2.7$ & $34.39 \pm 2.90$ & $>100$ & $>100$ \\
\hline $14 r$ & $\mathrm{C}_{2} \mathrm{H}_{5}$ & $\mathrm{Cl}$ & $\mathrm{NH}\left(\mathrm{CH}_{2}\right)_{2} \mathrm{NHC}_{2} \mathrm{H}_{5}$ & $\mathrm{~F}$ & $1.49 \pm 0.11$ & $1.43 \pm 0.21$ & $3.72 \pm 0.46$ & $1.22 \pm 0.10$ \\
\hline Sunitinib & $\mathrm{CH}_{3}$ & $\mathrm{CH}_{3}$ & $\mathrm{NH}\left(\mathrm{CH}_{2}\right)_{2} \mathrm{~N}\left(\mathrm{C}_{2} \mathrm{H}_{5}\right)_{2}$ & $\mathrm{~F}$ & $2.93 \pm 0.25$ & $2.60 \pm 0.18$ & $3.83 \pm 0.43$ & $4.79 \pm 0.62$ \\
\hline control & $\mathrm{Br}$ & $\mathrm{CH}_{3}$ & $\mathrm{NH}\left(\mathrm{CH}_{2}\right)_{2} \mathrm{~N}\left(\mathrm{C}_{2} \mathrm{H}_{5}\right)_{2}$ & $\mathrm{~F}$ & $>100$ & $83.39 \pm 9.76$ & $>100$ & $>100$ \\
\hline
\end{tabular}

First, compound 14a with a morpholine ring was examined. It was found to be effective towards A549, but ineffective on KB, K111 and NCI-H460. Compound 14b, a nitrogen analogue of 14a, and $N$-propyl amide 14d had $\mathrm{IC}_{50} \mathrm{~S}$ above $100 \mu \mathrm{M}$ towards all four cell lines. However, the use of hydrophilic $\mathrm{N}$-substituents as the basic side chain resulted in increased antitumor activities of the amides. The $\mathrm{IC}_{50} \mathrm{~s}$ were on the $\mu \mathrm{M}$ order of magnitude. Pleasantly, 14c, 14f, 14g and 14h were effective on the four different cell lines. It should be noticed that the $\mathrm{IC}_{50}$ values of $\mathbf{1 4 g}$ with a 2-(ethylamino)ethylcarbamoyl group was just $1 / 4-1 / 2$ of those of sunitinib, indicating the effectiveness of changing $\mathrm{N}$-substituents. By comparison with $\mathrm{N}, \mathrm{N}$-(2-(diethylamino)ethyl)amides, $N$-(2-(ethylamino)-ethyl)amides were much more active against the four cell lines, in particular against K111 and NCI-H460 (14g vs. 14h, 14o vs. 14p, 14q vs. 14r). On the basis of the crystallographic structure study [24], the functional group at C-4' position of pyrrole should be exposed to water. Perhaps the secondary amine structure and low steric hindrance of the terminal ethylamino group of $\mathrm{N}$-(2-(ethylamino)ethyl)amides are favourable for the formation of hydrogen-bonds with water to improve the solubility.

In order to examine the effects of chlorine atom on antitumor activities, two compounds $\mathbf{1 4 h}$ and 140 were synthesized by replacing one methyl group on the pyrrole ring of sunitinib with a chloro group. It was found that compounds $\mathbf{1 4 h}$ and $\mathbf{1 4 0}$ showed higher antitumor activities against A549 and 
KB than aunitinib. To improve the antitumor activities of compounds bearing chloro-substituted pyrroles, the effects of the number and position of chloro groups were studied. Antitumor agents $\mathbf{1 4 h}$, 14n and 14o bearing a monochloro-substituted pyrrole ring showed antitumor activities, while antitumor agent $\mathbf{1 4} \mathrm{m}$ bearing a dichloro-substituted pyrrole ring had no effects. The position of the chloro group did not seem to affect the activities greatly (cf. 14g vs. 14p, 14h vs. 14o). To investigate the effects of other functional groups on the chloropyrrole ring, several substituents (hydrogen, methyl and ethyl) at the C-3' position of pyrrole (compounds $\mathbf{1 4 n}, \mathbf{1 4 0}$ and $\mathbf{1 4 q}$ ) were investigated. It was found that compound $\mathbf{1 4 0}$ with a methyl group exhibited higher activity than the others. Bromine atom as the substituent on pyrrole control was found to show no antitumor activities.

Next, the C-5 position of indolin-2-one was modified. Replacing the fluoro in $\mathbf{1 4 h}$ with chloro (14i) led to a large increase in the potency towards A549 (from $1.87 \mu \mathrm{M}$ to $0.32 \mu \mathrm{M}$ ). Unfortunately, 14i showed little potency towards K111 and NCI-H460. When bromo, hydrogen or methyl groups were introduced to the $\mathrm{C}-5$ position of indolin-2-one $(\mathbf{1 4} \mathbf{j}, \mathbf{1 4 k}, \mathbf{1 4 l})$, the potency decreased substantially ( $\mathrm{IC}_{50} \mathrm{~s}$ above $\left.100 \mu \mathrm{M}\right)$.

In conclusion, compounds $14 \mathrm{c}, 14 \mathrm{f}, 14 \mathrm{~g}, 14 \mathrm{~h}, 14 \mathrm{i}, 14 \mathrm{p}$ and $14 \mathrm{r}$ were found to have potent antitumor activities, with $\mathbf{1 4 g}$ showing 3-4-fold higher inhibitory activities against $\mathrm{KB}$ and $\mathrm{K} 111\left(\mathrm{IC}_{50}=0.67 \mu \mathrm{M}\right.$, $1.19 \mu \mathrm{M}$ ) than sunitinib $\left(\mathrm{IC}_{50}=2.60 \mu \mathrm{M}, 3.83 \mu \mathrm{M}\right.$ ), while compounds $14 \mathbf{i}$ and $14 \mathbf{r}$ showed much higher inhibitory activities against $\mathrm{A} 549$ and NCI-H460 ( $\left.\mathrm{IC}_{50}=0.32 \mu \mathrm{M}, 1.22 \mu \mathrm{M}\right)$ than sunitinib $\left(\mathrm{IC}_{50}=2.93 \mu \mathrm{M}, 4.79 \mu \mathrm{M}\right)$, respectively.

Seven compounds in the $\mathbf{1 4 a - r}$ series with low $\mathrm{IC}_{50}$ values on the tumor cell lines were evaluated for their inhibition of VEGFR2 using an enzyme-linked immunosorbent assay (ELISA), and the data are summarized in Table 2. Except for compounds $14 \mathbf{i}$ and $\mathbf{1 4} \mathbf{r}$, the other compounds all exhibited good inhibitory effects against VEGFR2. In the compounds 14c, 14f, 14g, 14h and 14p bearing different $N$-pyrrole-4'-formamide substituents, $14 \mathrm{~g}$ and $\mathbf{1 4 p}$ bearing $N$-2-(ethylamino)ethyl groups showed greatly improved biological activities against VEGFR2. It was found that $\mathbf{1 4 h}$ which was synthesized by replacing one methyl group of Su11248 with chloro showed similar potency as Su11248 (sunitinib), but replacing the terminal $N$-diethyl of $\mathbf{1 4 h}$ with one ethyl group (compound $\mathbf{1 4 g}$ ) greatly improved the inhibition. The different positions of the chloro atoms on the pyrrole ring of $\mathbf{1 4 g}$ and 14p affected the activities. Compound 14g with a $3^{\prime}$-substituted chloropyrrole was more active than $14 p$ with a $5^{\prime}$-substituted chloropyrrole. In conclusion, compared with Su11248 ( $\left.\mathrm{IC}_{50}=6.5 \pm 3.0 \mathrm{nM}\right)$, 14f, 14g and 14p exhibited higher activities against VEGFR2. Among the three compounds, 14g $\left(\mathrm{IC}_{50}=5.0 \pm 1.1 \mathrm{nM}\right)$ showed the best potency. The data would suggest that the inhibition effects against other tyrosine kinase targets deserve to be evaluated in future studies.

Table 2. Inhibition activities of some 3-substituted-indolin-2-ones on VEGFR2.

\begin{tabular}{cccc}
\hline Compd. & IC $_{\mathbf{5 0}} \pm$ SD $(\mathbf{n M})$ & Compd. & IC $_{\mathbf{5 0}} \pm$ SD $(\mathbf{n M})$ \\
\hline $\mathbf{1 4 c}$ & $6.8 \pm 1.8$ & $\mathbf{1 4 i}$ & $11.2 \pm 2.6$ \\
$\mathbf{1 4 f}$ & $6.2 \pm 0.8$ & $\mathbf{1 4 p}$ & $6.0 \pm 1.2$ \\
$\mathbf{1 4 g}$ & $5.0 \pm 1.1$ & $\mathbf{1 4 r}$ & $8.7 \pm 1.3$ \\
$\mathbf{1 4 h}$ & $6.8 \pm 0.8$ & Sunitinib & $6.5 \pm 3.0$ \\
\hline
\end{tabular}


Cardiotoxicity is a known serious side effect of sunitinib. The pivotal phase III metastatic renal cell carcinoma trial indicated that $21 \%$ of sunitinib-treated patients experienced a decline in left ventricular ejection fraction (LVEF) to below normal [27]. The cardiotoxicity of the synthesized compounds was examined by evaluating their inhibition against hERG potassium currents in HEK239 cells and expressed as $\mathrm{IC}_{50}$, as shown in Figure 2. Compound $\mathbf{1 4 h}$, which exhibited good in vitro antitumor activities and has a chloro group at the pyrrole ring C-3' position, was selected as a candidate with low cardiotoxicity. Pleasantly, it was found that the cardiotoxicity of $\mathbf{1 4 h}\left(\mathrm{IC}_{50}=452.4 \mathrm{nM}\right)$ was about 9-fold lower than that of sunitinib $\left(\mathrm{IC}_{50}=50.3 \mathrm{nM}\right)$. The result indicated that the introduction of chlorine atom by replacing one methyl group on pyrrole ring of sunitinib with a chloro reduced the cardiotoxicity markedly. Next, compound $\mathbf{1 4 g}$ with the best inhibition against KB, K111 and VEGFR2 was also examined and its cardiotoxicity $\left(\mathrm{IC}_{50}=430.1 \mathrm{nM}\right)$ was about 8.5-fold lower than that of sunitinib $\left(\mathrm{IC}_{50}=50.3 \mathrm{nM}\right)$. Research into the cardiotoxicity of the other compounds is in progress, and the results will be reported in the future.

Figure 2. Inhibition against hERG potassium currents in HEK239 cells $\left(\mathrm{IC}_{50} \pm \mathrm{SD}\right)$.

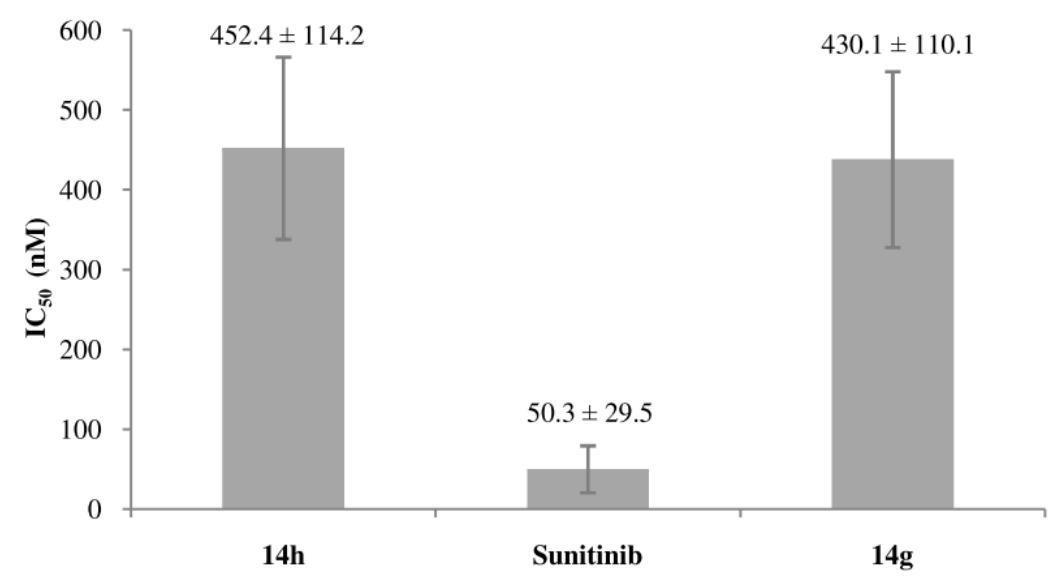

\section{Experimental}

\subsection{General}

${ }^{1} \mathrm{H}-\mathrm{NMR}$ and ${ }^{13} \mathrm{C}-\mathrm{NMR}$ were recorded on a Bruker ARX-400 spectrometer with tetramethylsilane as the internal standard and $\mathrm{CDCl}_{3}$ or DMSO- $d_{6}$ as the solvent. Melting points were determined on a Kruss KSP $\alpha$ melting point apparatus and were uncorrected. Mass Spectra (MS) and High Resolution Mass Spectra (HRMS) were measured on a Waters Q-T Micromass spectrometer. All compounds were routinely checked by thin layer chromatography (TLC) using Huanghai silica gel HSGF-254 glass plates. Reagents (analytical grade) were obtained from commercial suppliers and used without further purification, unless otherwise noted.

\subsection{Synthesis of 1,2-Dibromoethyl Acetate (2)}

To a solution of vinyl acetate $(\mathbf{1}, 18.4 \mathrm{~mL}, 0.20 \mathrm{~mol})$ in carbon tetrachloride $(10 \mathrm{~mL})$ was added bromine $(13.5 \mathrm{~mL}, 0.27 \mathrm{~mol})$ dropwise at $0{ }^{\circ} \mathrm{C}$. The mixture was stirred for $1 \mathrm{~h}$, and concentrated to give crude liquid product 2 which was used in the next reaction without purification. Yield: $48.4 \mathrm{~g}$ 
(98\%); ${ }^{1} \mathrm{H}-\mathrm{NMR}\left(\mathrm{CDCl}_{3}\right): \delta 2.19\left(\mathrm{~s}, 3 \mathrm{H}, \mathrm{CH}_{3}\right), 3.85-3.95\left(\mathrm{~m}, 2 \mathrm{H}, \mathrm{CH}_{2}\right), 6.71-6.74(\mathrm{~m}, 1 \mathrm{H}, \mathrm{CH})$; ${ }^{13} \mathrm{C}-\mathrm{NMR}\left(\mathrm{CDCl}_{3}\right): \delta 20.69,33.12,70.62,168.03$; MS (ESI): $246.86(\mathrm{M}+1)^{+}$.

\subsection{Synthesis of Ethyl 2-Methyl-1H-pyrrole-3-carboxylate (3)}

To a solution of 1,2-dibromoethyl acetate $(2,12.90 \mathrm{~g}, 0.15 \mathrm{~mol})$ and ethyl acetoacetate $(25.50 \mathrm{~mL}$, $0.2 \mathrm{~mol})$ was added $17 \%$ ammonia water $(100 \mathrm{~mL})$ dropwise at $0-10{ }^{\circ} \mathrm{C}$ during $2 \mathrm{~h}$. Then the mixture was stirred at room temperature overnight. The precipitated pure 3 was collected by filtration, washed with water and dried under vacuum. Light yellow solid; Yield: $11.5 \mathrm{~g}(50 \%)$; m.p. 78.5-79.2 ${ }^{\circ} \mathrm{C} ;{ }^{1} \mathrm{H}-\mathrm{NMR}$ $\left(\mathrm{CDCl}_{3}\right): \delta 1.36\left(\mathrm{t}, J=7.13 \mathrm{~Hz}, 3 \mathrm{H}, \mathrm{CH}_{3}\right), 2.54\left(\mathrm{~s}, 3 \mathrm{H}, \mathrm{CH}_{3}\right), 4.29\left(\mathrm{q}, J=7.13 \mathrm{~Hz}, 2 \mathrm{H}, \mathrm{CH}_{2}\right), 6.57-6.59$ $\left(\mathrm{m}, 2 \mathrm{H}\right.$, pyrrole), $8.55(\mathrm{~s}, 1 \mathrm{H}, \mathrm{NH}) ;{ }^{13} \mathrm{C}-\mathrm{NMR}\left(\mathrm{CDCl}_{3}\right): \delta 13.23,14.52,59.40,110.50,111.82,115.78$, 135.25, 165.85; MS (ESI): $154.08(\mathrm{M}+1)^{+}$.

\subsection{General Procedure for Synthesis of Ethyl 3-Substituted-acrylates 8a-c}

A mixture of ylide 7 (10 g, $0.03 \mathrm{~mol})$ and aldehydes (formaldehyde, acetaldehyde, propaldehyde) $(0.03 \mathrm{~mol})$ in benzene $(30 \mathrm{~mL})$ was refluxed for $5-6 \mathrm{~h}$. Then the mixture was cooled to room temperature and filtrated. The filtrate was concentrated and purified by flash column chromatography to obtain liquid product $(\mathrm{PE} / \mathrm{EA}=15 / 1)$.

Ethyl acrylate (8a). Yield: $2.46 \mathrm{~g}(87 \%) ;{ }^{1} \mathrm{H}-\mathrm{NMR}\left(\mathrm{CDCl}_{3}\right): \delta 1.22\left(\mathrm{t}, J=7.41 \mathrm{~Hz}, 3 \mathrm{H}, \mathrm{CH}_{3}\right), 4.15(\mathrm{q}$, $\left.J=7.41 \mathrm{~Hz}, 2 \mathrm{H}, \mathrm{CH}_{2}\right), 5.56-5.71(\mathrm{~m}, 1 \mathrm{H}, \mathrm{CH}), 6.06-6.12(\mathrm{~m}, 1 \mathrm{H}, \mathrm{CH}), 6.27-6.31(\mathrm{~m}, 1 \mathrm{H}, \mathrm{CH})$; ${ }^{13} \mathrm{C}-\mathrm{NMR}\left(\mathrm{CDCl}_{3}\right): \delta 13.82,60.15,127.21,132.78,166.80$; MS (ESI): $101.10(\mathrm{M}+1)^{+}$.

Ethyl but-2-enoate (8b). Yield: $2.85 \mathrm{~g}(89 \%) ;{ }^{1} \mathrm{H}-\mathrm{NMR}\left(\mathrm{CDCl}_{3}\right): \delta 1.25\left(\mathrm{t}, J=7.33 \mathrm{~Hz}, 3 \mathrm{H}, \mathrm{CH}_{3}\right)$, 2.01-2.06 (m, 3H, $\left.\mathrm{CH}_{3}\right), 4.25$ (q, J = 7.33 Hz, 2H, $\left.\mathrm{CH}_{2}\right), 5.83-5.88(\mathrm{~m}, 1 \mathrm{H}, \mathrm{CH}), 6.78-6.84(\mathrm{~m}, 1 \mathrm{H}, \mathrm{CH})$; ${ }^{13} \mathrm{C}-\mathrm{NMR}\left(\mathrm{CDCl}_{3}\right): \delta 14.22,18.25,61.41,143.23,146.81,166.52 ; \mathrm{MS}(\mathrm{ESI}): 115.12(\mathrm{M}+1)^{+}$.

Ethyl pent-2-enoate (8c). Yield: $3.31 \mathrm{~g}(92 \%) ;{ }^{1} \mathrm{H}-\mathrm{NMR}\left(\mathrm{CDCl}_{3}\right): \delta 1.04\left(\mathrm{t}, J=7.44 \mathrm{~Hz}, 3 \mathrm{H}, \mathrm{CH}_{3}\right)$, $1.26\left(\mathrm{t}, J=7.44 \mathrm{~Hz}, 3 \mathrm{H}, \mathrm{CH}_{3}\right), 2.16-2.24\left(\mathrm{~m}, 2 \mathrm{H}, \mathrm{CH}_{2}\right), 4.16\left(\mathrm{q}, J=7.44 \mathrm{~Hz}, 2 \mathrm{H}, \mathrm{CH}_{2}\right), 5.76-5.81$ $(\mathrm{m}, 1 \mathrm{H}, \mathrm{CH}), 6.96-7.03(\mathrm{~m}, 1 \mathrm{H}, \mathrm{CH}) ;{ }^{13} \mathrm{C}-\mathrm{NMR}\left(\mathrm{CDCl}_{3}\right): \delta 12.10,14.21,25.21,60.02,120.38,150.50$, 166.74; MS (ESI): $129.15(\mathrm{M}+1)^{+}$.

\subsection{General Procedure for Synthesis of Ethyl 4-Alkyl/H-1H-pyrrole-3-carboxylates 9a-c}

A suspension of TosMIC (10.5 g, $0.053 \mathrm{~mol})$ and ethyl 3-substituted-acrylates 8a-c (0.056 mol) in dry ethyl ether/DMSO $(100 \mathrm{~mL} / 50 \mathrm{~mL})$ was added dropwise under argon to a suspension of $\mathrm{NaH}(3.75 \mathrm{~g}$, $0.094 \mathrm{~mol})$ in ethyl ether $(50 \mathrm{~mL})$ at room temperature. Then the mixture was stirred for $4-5 \mathrm{~h}$. Ice water $(200 \mathrm{~mL})$ was added into the mixture. The aqueous phase was extracted with ethyl ether $(3 \times 100 \mathrm{~mL})$. The organic phase was dried with anhydrous $\mathrm{Na}_{2} \mathrm{SO}_{4}$, concentrated under vacuum to get light brown liquid compounds $\mathbf{9 a - c .}$

Ethyl 1H-pyrrole-3-carboxylate (9a). Yield: $6.5 \mathrm{~g}(88 \%) ;{ }^{1} \mathrm{H}-\mathrm{NMR}\left(\mathrm{CDCl}_{3}\right): \delta 1.36(\mathrm{t}, J=7.14 \mathrm{~Hz}$, $\left.3 \mathrm{H}, \mathrm{CH}_{3}\right), 4.31\left(\mathrm{q}, J=7.14 \mathrm{~Hz}, 2 \mathrm{H}, \mathrm{CH}_{2}\right), 6.65-6.67(\mathrm{~m}, 1 \mathrm{H}, \mathrm{CH}), 6.76-6.79(\mathrm{~m}, 1 \mathrm{H}, \mathrm{CH}), 7.45-7.46$ 
$(\mathrm{m}, 1 \mathrm{H}, \mathrm{CH}), 9.86(\mathrm{~s}, 1 \mathrm{H}, \mathrm{NH}) ;{ }^{13} \mathrm{C}-\mathrm{NMR}\left(\mathrm{CDCl}_{3}\right): \delta 14.43,59.97,109.46,115.98,119.28,123.97$, 166.11; MS (ESI): $140.07(\mathrm{M}+1)^{+}$.

Ethyl 4-methyl-1H-pyrrole-3-carboxylate (9b). Yield: $7.3 \mathrm{~g}(90 \%) ;{ }^{1} \mathrm{H}-\mathrm{NMR}\left(\mathrm{CDCl}_{3}\right): \delta 1.28(\mathrm{t}$, $\left.J=7.12 \mathrm{~Hz}, 3 \mathrm{H}, \mathrm{CH}_{3}\right), 2.30\left(\mathrm{~s}, 3 \mathrm{H}, \mathrm{CH}_{3}\right), 4.21\left(\mathrm{q}, J=7.12 \mathrm{~Hz}, 2 \mathrm{H}, \mathrm{CH}_{2}\right), 6.54-6.57(\mathrm{~m}, 1 \mathrm{H}, \mathrm{CH})$, 7.37-7.39 (m, 1H, CH), $9.01(\mathrm{~s}, 1 \mathrm{H}, \mathrm{NH}) ;{ }^{13} \mathrm{C}-\mathrm{NMR}\left(\mathrm{CDCl}_{3}\right): \delta 12.66,14.39,50.78,114.28,117.54$, 120.93, 124.61. 166.45; MS (ESI): $154.06(\mathrm{M}+1)^{+}$.

Ethyl 4-ethyl-1H-pyrrole-3-carboxylate (9c). Yield: $7.9 \mathrm{~g}(89 \%) ;{ }^{1} \mathrm{H}-\mathrm{NMR}\left(\mathrm{CDCl}_{3}\right): \delta 1.21(\mathrm{t}, J=7.43 \mathrm{~Hz}$, $\left.3 \mathrm{H}, \mathrm{CH}_{3}\right), 1.34\left(\mathrm{t}, J=7.43 \mathrm{~Hz}, 3 \mathrm{H}, \mathrm{CH}_{3}\right), 2.76$ (q, $\left.J=7.43 \mathrm{~Hz}, 2 \mathrm{H}, \mathrm{CH}_{2}\right), 4.27\left(\mathrm{q}, J=7.43 \mathrm{~Hz}, 2 \mathrm{H}, \mathrm{CH}_{2}\right.$ ), 6.54-6.56 (m, 1H, CH), 7.38-7.40 (m, 1H, CH), $8.65(\mathrm{~s}, 1 \mathrm{H}, \mathrm{NH}) ;{ }^{13} \mathrm{C}-\mathrm{NMR}\left(\mathrm{CDCl}_{3}\right): \delta 14.47,14.59$, $19.52,59.38,114.12,116.14,124.64,128.05,165.68$; MS (ESI): $168.08(\mathrm{M}+1)^{+}$.

\subsection{General Procedure for Synthesis of Ethyl 5-Formyl-2/4-alkyl-1H-pyrrole-3-carboxylates 4,10a-c}

The Vilsmeier reagent was prepared by treatment of dry DMF $(4.5 \mathrm{~mL}, 0.057 \mathrm{~mol})$ with $\mathrm{POCl}_{3}(5.4 \mathrm{~mL}$, $0.057 \mathrm{~mol}$ ) at $0{ }^{\circ} \mathrm{C}$ and stirred for another hour at room temperature. In a flask, a solution of ethyl 2/4-alkyl-1H-pyrrole-3-carboxylates 3,9a-c $(0.039 \mathrm{~mol})$ in DMF $(10 \mathrm{~mL})$ was treated with the freshly prepared Vilsmeier reagent at $0{ }^{\circ} \mathrm{C}$. The resulting mixture was stirred for another hour at room temperature, then poured into ice $(50 \mathrm{~g})$, adjusted the $\mathrm{pH}$ to $7-8$ with $10 \mathrm{~N}$ aqueous $\mathrm{NaOH}$. The resulting mixture was heated to $60{ }^{\circ} \mathrm{C}$ for two h. The precipitated light yellow solid compounds $\mathbf{4 , 1 0 a - c}$ were collected by filtration and dried under vacuum.

Ethyl 5-formyl-2-methyl-1H-pyrrole-3-carboxylate (4). Light yellow solid; Yield: $6.4 \mathrm{~g}$ (90\%); m.p. 132.5-133.3 ${ }^{\circ} \mathrm{C} ;{ }^{1} \mathrm{H}-\mathrm{NMR}\left(\mathrm{CDCl}_{3}\right): \delta 1.38\left(\mathrm{t}, J=7.13 \mathrm{~Hz}, 3 \mathrm{H}, \mathrm{CH}_{3}\right), 2.66\left(\mathrm{~s}, 3 \mathrm{H}, \mathrm{CH}_{3}\right), 4.32(\mathrm{q}$, $\left.J=7.13 \mathrm{~Hz}, 2 \mathrm{H}, \mathrm{CH}_{2}\right), 7.40-7.41(\mathrm{~m}, 1 \mathrm{H}, \mathrm{CH}), 9.42(\mathrm{~s}, 1 \mathrm{H}, \mathrm{CHO}), 10.99(\mathrm{~s}, 1 \mathrm{H}, \mathrm{NH}) ;{ }^{13} \mathrm{C}-\mathrm{NMR}$ $\left(\mathrm{CDCl}_{3}\right): \delta 13.55,14.41,60.02,115.49,124.47,130.44,144.01,164.30,179.17$; MS (ESI): $182.13(\mathrm{M}+1)^{+}$.

Ethyl 5-formyl-1H-pyrrole-3-carboxylate (10a). Light yellow solid; Yield: 5.6 g (85\%); m.p. 84.1-85.1 ${ }^{\circ} \mathrm{C}$; ${ }^{1} \mathrm{H}-\mathrm{NMR}\left(\mathrm{CDCl}_{3}\right): \delta 1.29\left(\mathrm{t}, J=7.13 \mathrm{~Hz}, 3 \mathrm{H}, \mathrm{CH}_{3}\right), 4.25\left(\mathrm{q}, J=7.13 \mathrm{~Hz}, 2 \mathrm{H}, \mathrm{CH}_{2}\right), 7.34-7.35(\mathrm{~m}, 1 \mathrm{H}$, $\mathrm{CH}), 7.66-7.67(\mathrm{~m}, 1 \mathrm{H}, \mathrm{CH}), 9.49(\mathrm{~s}, 1 \mathrm{H}, \mathrm{CHO}), 10.42(\mathrm{~s}, 1 \mathrm{H}, \mathrm{NH}) ;{ }^{13} \mathrm{C}-\mathrm{NMR}\left(\mathrm{CDCl}_{3}\right): \delta 14.37$, 60.39, 119.18, 121.62, 129.97, 133.05, 163.63, 180.04; MS (ESI): $168.07(\mathrm{M}+1)^{+}$.

Ethyl 5-formyl-4-methyl-1H-pyrrole-3-carboxylate (10b). Light yellow solid; Yield: 6.6 g (93\%); m.p. 123.5-125.2 ${ }^{\circ} \mathrm{C} ;{ }^{1} \mathrm{H}-\mathrm{NMR}\left(\mathrm{CDCl}_{3}\right): \delta 1.25\left(\mathrm{t}, J=7.15 \mathrm{~Hz}, 3 \mathrm{H}, \mathrm{CH}_{3}\right), 2.63\left(\mathrm{~s}, 3 \mathrm{H}, \mathrm{CH}_{3}\right), 4.23(\mathrm{q}$, $\left.J=7.15 \mathrm{~Hz}, 2 \mathrm{H}, \mathrm{CH}_{2}\right), 7.66-7.67(\mathrm{~m}, 1 \mathrm{H}, \mathrm{CH}), 9.73(\mathrm{~s}, 1 \mathrm{H}, \mathrm{CHO}), 10.05(\mathrm{~s}, 1 \mathrm{H}, \mathrm{NH}) ;{ }^{13} \mathrm{C}-\mathrm{NMR}$ $\left(\mathrm{CDCl}_{3}\right): \delta 9.88,11.23,51.15,117.11,130.13,130.54,133.88,164.51,178.36$; MS (ESI): $182.09(\mathrm{M}+1)^{+}$.

Ethyl 4-ethyl-5-formyl-1H-pyrrole-3-carboxylate (10c). Light yellow solid; Yield: $6.6 \mathrm{~g}$ (86\%); m.p. 84.5-86.0 ${ }^{\circ} \mathrm{C} ;{ }^{1} \mathrm{H}-\mathrm{NMR}\left(\mathrm{CDCl}_{3}\right): \delta 1.22\left(\mathrm{t}, J=7.47 \mathrm{~Hz}, 3 \mathrm{H}, \mathrm{CH}_{3}\right), 1.29\left(\mathrm{t}, J=7.47 \mathrm{~Hz}, 3 \mathrm{H}, \mathrm{CH}_{3}\right), 3.01$ (q, $\left.J=7.47 \mathrm{~Hz}, 2 \mathrm{H}, \mathrm{CH}_{2}\right), 4.24\left(\mathrm{q}, J=7.47 \mathrm{~Hz}, 2 \mathrm{H}, \mathrm{CH}_{2}\right), 7.56-7.57(\mathrm{~m}, 1 \mathrm{H}, \mathrm{CH}), 9.64(\mathrm{~s}, 1 \mathrm{H}, \mathrm{CHO})$, $10.32(\mathrm{~s}, 1 \mathrm{H}, \mathrm{NH}) ;{ }^{13} \mathrm{C}-\mathrm{NMR}\left(\mathrm{CDCl}_{3}\right): \delta 14.36,16.92,17.59,59.96,116.58,129.86,130.36,140.59$, 163.83, 178.35; MS (ESI): $196.15(\mathrm{M}+1)^{+}$. 


\subsection{General Procedure for Synthesis of Ethyl Chloro-substituted-5-formyl-1H-pyrrole-3-carboxylates}

\section{5, 11a-d}

Sulfuryl chloride $(1.66 \mathrm{~mL}, 0.025 \mathrm{~mol}$, for the synthesis of 11a-c, 5, $4.00 \mathrm{~mL}, 0.060 \mathrm{~mol}$, for synthesis of 11d) was added dropwise within 10-15 min to the solution of ethyl 2/4-alkyl-5-formy- $1 \mathrm{H}$ pyrrole-3-carboxylates $\mathbf{4}, \mathbf{1 0 a}-\mathbf{c}(0.020 \mathrm{~mol})$ dissolved in acetic acid $(20 \mathrm{~mL})$ cooled with an ice bath. After addition, the mixture was stirred for 30-60 min at room temperature, and poured into ice water (100 mL). The precipitated products 5, 11a-d were collected by filtration, dried under vacuum, purified by flash column chromatography $(\mathrm{PE} / \mathrm{EA}=5 / 1)$.

Ethyl 4-chloro-5-formyl-2-methyl-1H-pyrrole-3-carboxylate (5). Light orange solid; Yield: $1.9 \mathrm{~g}$ (44\%); m.p. 189.3-190.0 ${ }^{\circ} \mathrm{C} ;{ }^{1} \mathrm{H}-\mathrm{NMR}\left(\mathrm{CDCl}_{3}\right): \delta 1.36\left(\mathrm{t}, J=7.13 \mathrm{~Hz}, 3 \mathrm{H}, \mathrm{CH}_{3}\right), 2.65\left(\mathrm{~s}, 3 \mathrm{H}, \mathrm{CH}_{3}\right), 4.30$ (q, $\left.J=7.13 \mathrm{~Hz}, 2 \mathrm{H}, \mathrm{CH}_{2}\right), 9.45(\mathrm{~s}, 1 \mathrm{H}, \mathrm{CHO}), 10.09$ (s, $\left.1 \mathrm{H}, \mathrm{NH}\right) ;{ }^{13} \mathrm{C}-\mathrm{NMR}\left(\mathrm{CDCl}_{3}\right): \delta 12.55,14.41$, 59.02, 116.32, 124.87, 129.78, 143.01, 162.33, 179.08; MS (ESI): $216.04(\mathrm{M}+1)^{+}$.

Ethyl 2-chloro-5-formyl-1H-pyrrole-3-carboxylate (11a). Light yellow solid; Yield: $1.8 \mathrm{~g}$ (45\%); m.p. 123.5-125.9 ${ }^{\circ} \mathrm{C} ;{ }^{1} \mathrm{H}-\mathrm{NMR}\left(\mathrm{CDCl}_{3}\right): \delta 1.40\left(\mathrm{t}, J=7.13 \mathrm{~Hz}, 3 \mathrm{H}, \mathrm{CH}_{3}\right), 4.36\left(\mathrm{q}, J=7.13 \mathrm{~Hz}, 2 \mathrm{H}, \mathrm{CH}_{2}\right)$, 7.40-7.41 (m, 1H, CH), $9.48(\mathrm{~s}, 1 \mathrm{H}, \mathrm{CHO}), 9.96(\mathrm{~s}, 1 \mathrm{H}, \mathrm{NH}) ;{ }^{13} \mathrm{C}-\mathrm{NMR}\left(\mathrm{CDCl}_{3}\right): \delta 14.31,60.70$, 114.79, 122.26, 122.31, 130.40, 162.13, 178.67; MS (ESI): $202.09(\mathrm{M}+1)^{+}$.

Ethyl 2-chloro-5-formyl-4-methyl-1H-pyrrole-3-carboxylate (11b). Light yellow solid; Yield: $2.2 \mathrm{~g}$ (50\%); m.p. 173.5-174.3 ${ }^{\circ} \mathrm{C} ;{ }^{1} \mathrm{H}-\mathrm{NMR}\left(\mathrm{CDCl}_{3}\right): \delta 1.22\left(\mathrm{t}, J=7.13 \mathrm{~Hz}, 3 \mathrm{H}, \mathrm{CH}_{3}\right), 2.50\left(\mathrm{~s}, 3 \mathrm{H}, \mathrm{CH}_{3}\right)$, 4.22 (q, $\left.J=7.13 \mathrm{~Hz}, 2 \mathrm{H}, \mathrm{CH}_{2}\right), 9.58(\mathrm{~s}, 1 \mathrm{H}, \mathrm{CHO}), 9.90(\mathrm{~s}, 1 \mathrm{H}, \mathrm{NH}) ;{ }^{13} \mathrm{C}-\mathrm{NMR}\left(\mathrm{CDCl}_{3}\right): \delta 10.61$, $11.25,51.37,113.35,128.46,129.17,134.85,163.36,177.15$; MS (ESI): $216.04(\mathrm{M}+1)^{+}$.

Ethyl 2-chloro-4-ethyl-5-formyl-1H-pyrrole-3-carboxylate (11c). Light yellow solid; Yield: $1.9 \mathrm{~g}$ (43\%); m.p. 109.5-111.8 ${ }^{\circ} \mathrm{C} ;{ }^{1} \mathrm{H}-\mathrm{NMR}\left(\mathrm{CDCl}_{3}\right)$ : $\delta 1.29\left(\mathrm{t}, J=7.47 \mathrm{~Hz}, 3 \mathrm{H}, \mathrm{CH}_{3}\right), 1.40(\mathrm{t}, J=7.47 \mathrm{~Hz}$, $\left.3 \mathrm{H}, \mathrm{CH}_{3}\right), 3.07$ (q, J = 7.47 Hz, 2H, $\left.\mathrm{CH}_{2}\right), 4.37$ (q, J=7.47 Hz, 2H, $\mathrm{CH}_{2}$ ), 9.66 (s, 1H, CHO), 10.51 (s, $1 \mathrm{H}, \mathrm{NH}) ;{ }^{13} \mathrm{C}-\mathrm{NMR}\left(\mathrm{CDCl}_{3}\right): \delta 14.22,16.89,18.11,60.39,112.67,127.72,129.59,141.85,162.73$, 177.28; MS (ESI): $230.06(\mathrm{M}+1)^{+}$.

Ethyl 2,4-dichloro-5-formyl-1H-pyrrole-3-carboxylate (11d). Light yellow solid; Yield: $1.6 \mathrm{~g}$ (33\%); m.p. 173.5-174.9 ${ }^{\circ} \mathrm{C} ;{ }^{1} \mathrm{H}-\mathrm{NMR}\left(\mathrm{CDCl}_{3}\right): \delta 1.26\left(\mathrm{t}, J=7.14 \mathrm{~Hz}, 3 \mathrm{H}, \mathrm{CH}_{3}\right), 4.30(\mathrm{q}, J=7.14 \mathrm{~Hz}, 2 \mathrm{H}$, $\left.\mathrm{CH}_{2}\right), 9.65(\mathrm{~s}, 1 \mathrm{H}, \mathrm{CHO}), 9.99(\mathrm{~s}, 1 \mathrm{H}, \mathrm{NH}) ;{ }^{13} \mathrm{C}-\mathrm{NMR}\left(\mathrm{CDCl}_{3}\right): \delta 13.67,58.35,114.78,122.36,124.67$, 129.38, 165.14, 177.29; MS (ESI): $237.03(\mathrm{M}+1)^{+}$.

3.8. General Procedure for Synthesis of Chloro-substituted-5-formyl-1H-pyrrole-3-carboxylic acids $\mathbf{6}$, $12 \mathbf{a}-\mathbf{d}$

Ethyl chloro-substituted-5-formyl-1H-pyrrole-3-carboxylates 5, 11a-d (0.014 mol) were dissolved in a solution of $\mathrm{NaOH}(2.80 \mathrm{~g}, 0.070 \mathrm{~mol})$ in $\mathrm{MeOH} / \mathrm{H}_{2} \mathrm{O}(2 \mathrm{~mL} / 30 \mathrm{~mL})$, and the mixture was refluxed for two hours, then extracted with dichloromethane $(20 \mathrm{~mL} \times 2)$. The aqueous layer was acidified with $18 \%$ hydrochloric acid to $\mathrm{pH}=2-3$ and the precipitated pure crystals $\mathbf{6}, \mathbf{1 2 a}-\mathbf{d}$ were collected by filtration, washed with water, and dried under vacuum. 
4-Chloro-5-formyl-2-methyl-1H-pyrrole-3-carboxylic acid (6). Light yellow solid; Yield: $2.0 \mathrm{~g}$ (75\%); m.p. $>290{ }^{\circ} \mathrm{C} ;{ }^{1} \mathrm{H}-\mathrm{NMR}\left(\mathrm{DMSO}-d_{6}\right): \delta 2.45$ (s, 3H, $\left.\mathrm{CH}_{3}\right), 9.59$ (s, $\left.1 \mathrm{H}, \mathrm{CHO}\right), 12.48(\mathrm{~s}, 1 \mathrm{H}, \mathrm{NH}), 13.21$ $(\mathrm{s}, 1 \mathrm{H}, \mathrm{COOH}) ;{ }^{13} \mathrm{C}-\mathrm{NMR}$ (DMSO- $\left.d_{6}\right): \delta 14.25,112.21,127.11,131.12,143.03,164.34,177.54$; MS (ESI): $188.06(\mathrm{M}+1)^{+}$.

2-Chloro-5-formyl-1H-pyrrole-3-carboxylic acid (12a). Light yellow solid; Yield: $19.4 \mathrm{~g}$ (80\%); m.p. $>290{ }^{\circ} \mathrm{C} ;{ }^{1} \mathrm{H}-\mathrm{NMR}\left(\mathrm{DMSO}-d_{6}\right): \delta 7.38-7.40(\mathrm{~m}, 1 \mathrm{H}, \mathrm{CH}), 9.45(\mathrm{~s}, 1 \mathrm{H}, \mathrm{CHO}), 12.67(\mathrm{~s}, 1 \mathrm{H}, \mathrm{NH})$, $13.51(\mathrm{~s}, 1 \mathrm{H}, \mathrm{COOH}) ;{ }^{13} \mathrm{C}-\mathrm{NMR}$ (DMSO- $\left.d_{6}\right): \delta 114.24,122.88,127.89,131.48,163.66,180.11$; MS (ESI): $174.01(\mathrm{M}+1)^{+}$.

2-Chloro-5-formyl-4-methyl-1H-pyrrole-3-carboxylic acid (12b). Light yellow solid; Yield: $2.4 \mathrm{~g}$ (92\%); m.p. > $290{ }^{\circ} \mathrm{C} ;{ }^{1} \mathrm{H}-\mathrm{NMR}$ (DMSO-d $)$ ) $\delta 2.49$ (s, 3H, $\mathrm{CH}_{3}$ ), 9.66 (s, $\left.1 \mathrm{H}, \mathrm{CHO}\right), 12.64(\mathrm{~s}, 1 \mathrm{H}, \mathrm{NH}), 13.21$ $(\mathrm{s}, 1 \mathrm{H}, \mathrm{COOH}) ;{ }^{13} \mathrm{C}-\mathrm{NMR}$ (DMSO- $\left.d_{6}\right): \delta 10.90,113.06,128.09,129.19,133.76,164.42,178.80$; MS (ESI): $188.04(\mathrm{M}+1)^{+}$.

2-Chloro-4-ethyl-5-formyl-1H-pyrrole-3-carboxylic acid (12c). Light yellow solid; Yield: $2.5 \mathrm{~g}$ (89\%); m.p. 248.3-250.2 ${ }^{\circ} \mathrm{C} ;{ }^{1} \mathrm{H}-\mathrm{NMR}$ (DMSO-d $)_{6}$ ): $\delta 1.14\left(\mathrm{t}, J=7.28 \mathrm{~Hz}, 3 \mathrm{H}, \mathrm{CH}_{3}\right.$ ), 2.99 (q, $J=7.28 \mathrm{~Hz}, 2 \mathrm{H}$, $\mathrm{CH}_{2}$ ), 9.65 (s, $\left.1 \mathrm{H}, \mathrm{CHO}\right), 12.63(\mathrm{~s}, 1 \mathrm{H}, \mathrm{NH}), 13.20(\mathrm{~s}, 1 \mathrm{H}, \mathrm{COOH}) ;{ }^{13} \mathrm{C}-\mathrm{NMR}$ (DMSO- $\left.d_{6}\right): \delta 17.24$, 17.82, 112.22, 128.07, 128.42, 140.35, 164.25, 178.70; MS (ESI): $202.10(\mathrm{M}+1)^{+}$.

2,4-Dichloro-5-formyl-1H-pyrrole-3-carboxylic acid (12d). Light yellow solid; Yield: $2.4 \mathrm{~g}$ (81\%); m.p. $>290{ }^{\circ} \mathrm{C} ;{ }^{1} \mathrm{H}-\mathrm{NMR}$ (DMSO- $\left.d_{6}\right): \delta 9.76$ (s, 1H, CHO), 12.32 (s, 1H, NH), 13.15 (s, 1H, COOH); ${ }^{13} \mathrm{C}-\mathrm{NMR}\left(\mathrm{DMSO}-d_{6}\right): \delta 114.28,122.75,124.37,128.93,165.09,178.07$; MS (ESI): $209.01(\mathrm{M}+1)^{+}$.

\subsection{General Procedure for Synthesis of 3-Substituted-indolin-2-ones 14a-r}

To a solution of compounds $\mathbf{6}, \mathbf{1 2 a}-\mathbf{d}(0.006 \mathrm{~mol})$ in DMF $(10 \mathrm{~mL})$ were added amines $(0.0072 \mathrm{~mol})$, $\mathrm{EDC} \cdot \mathrm{HCl}(1.73 \mathrm{~g}, 0.009 \mathrm{~mol}), \mathrm{HOBt}(1.22 \mathrm{~g}, 0.009 \mathrm{~mol})$ and $\mathrm{Et}_{3} \mathrm{~N}(1.22 \mathrm{~g}, 0.012 \mathrm{~mol})$. The mixture was stirred for $20 \mathrm{~h}$ at room temperature and poured into water $(20 \mathrm{~mL})$. The mixture was extracted with dichloromethane $(20 \mathrm{~mL} \times 3)$. The organic phase was washed with saturated aqueous $\mathrm{NaCl}$ $(20 \mathrm{~mL} \times 2)$, dried with anhydrous $\mathrm{Na}_{2} \mathrm{SO}_{4}$, and concentrated to get the crude products $\mathbf{1 3 a}-\mathbf{n}$ which were used in the next step without purification. To a solution of 13a-n dissolved in ethanol $(8.0 \mathrm{~mL})$ were added indolin-2-ones $(0.0066 \mathrm{~mol})$ and $\mathrm{Et}_{3} \mathrm{~N}(0.0010 \mathrm{~mol})$. The mixture was heated to reflux for 2-4 h. The precipitated crystals were collected by filtration, purified by recrystallization from ethanol or by flash column chromatography $(\mathrm{DCM} / \mathrm{MeOH}=15 / 1 \sim 12 / 1)$, and dried under vacuum at $80-90{ }^{\circ} \mathrm{C}$ to get target compounds 14a-r.

(Z)-4-Chloro-5-((5-fluoro-2-oxoindolin-3-ylidene)methyl)-2-methyl-N-(2-morpholinoethyl)-1H-pyrrole -3-carboxamide (14a). Yellow solid; Yield: $0.8 \mathrm{~g}(32 \%)$; m.p. $268.5-269.7{ }^{\circ} \mathrm{C} ;{ }^{1} \mathrm{H}-\mathrm{NMR}\left(\mathrm{CDCl}_{3}\right): \delta 2.56$ $\left(\mathrm{t}, J=7.12 \mathrm{~Hz}, 4 \mathrm{H}, \mathrm{CH}_{2} \times 2\right), 2.63\left(\mathrm{t}, J=5.82 \mathrm{~Hz}, 2 \mathrm{H}, \mathrm{CH}_{2}\right), 2.71\left(\mathrm{~s}, 3 \mathrm{H}, \mathrm{CH}_{3}\right), 3.55-3.59(\mathrm{~m}, 2 \mathrm{H}$, $\left.\mathrm{CH}_{2}\right), 3.77\left(\mathrm{t}, J=7.12 \mathrm{~Hz}, 4 \mathrm{H}, \mathrm{CH}_{2} \times 2\right), 6.83-7.70(\mathrm{~m}, 6 \mathrm{H}$, aromatic, vinyl, CONH, indolin-2-one $\mathrm{NH}), 13.58(\mathrm{~s}, 1 \mathrm{H}$, pyrrole $\mathrm{NH}) ;{ }^{13} \mathrm{C}-\mathrm{NMR}\left(\mathrm{CDCl}_{3}\right): \delta 14.20,36.30,53.58,57.30,66.80,107.32$, 110.96, 117.99, 118.67, 118.82, 122.61, 124.46, 125.24, 126.53, 135.86, 137.29, 157.11, 162.50, 169.95; HRMS (ESI) $\mathrm{m} / z(\mathrm{M}+\mathrm{H})^{+}$: calculated for $\mathrm{C}_{21} \mathrm{H}_{23} \mathrm{ClFN}_{4} \mathrm{O}_{3}{ }^{+}: 433.1443$, found 433.1440 . 
(Z)-3-((3-Chloro-5-methyl-4-(4-methylpiperazine-1-carbonyl)-1H-pyrrol-2-yl)methylene)-5-fluoroindolin2-one (14b). Yellow solid; Yield: $0.8 \mathrm{~g}(32 \%)$; m.p. $276.7-278.5{ }^{\circ} \mathrm{C} ;{ }^{1} \mathrm{H}-\mathrm{NMR}\left(\mathrm{CDCl}_{3}\right): \delta 2.36(\mathrm{~s}, 3 \mathrm{H}$, $\left.\mathrm{CH}_{3}\right), 2.45\left(\mathrm{~s}, 3 \mathrm{H}, \mathrm{CH}_{3}\right), 2.50\left(\mathrm{t}, J=7.12 \mathrm{~Hz}, 4 \mathrm{H}, \mathrm{CH}_{2} \times 2\right), 3.10\left(\mathrm{t}, J=7.12 \mathrm{~Hz}, 4 \mathrm{H}, \mathrm{CH}_{2} \times 2\right)$, 6.82-7.41 (m, 4H, aromatic, vinyl, $\mathrm{CONH}), 7.99$ (s, 1H, indolin-2-one $\mathrm{NH}), 13.48$ (s, 1H, pyrrole $\mathrm{NH}$ ); ${ }^{13} \mathrm{C}-\mathrm{NMR}\left(\mathrm{CDCl}_{3}\right): \delta 13.22,46.08,47.26,54.88,105.97,110.20,113.76,116.87,118.13,119.85$, $122.58,124.48,126.71,133.75,135.39,158.02,163.83,169.76$; HRMS (ESI) $m / z(\mathrm{M}+\mathrm{H})^{+}:$calculated for $\mathrm{C}_{20} \mathrm{H}_{21} \mathrm{ClFN}_{4} \mathrm{O}_{2}^{+}$: 403.1335, found 403.1337 .

(Z)-N-(azetidin-3-yl)-4-chloro-5-((5-fluoro-2-oxoindolin-3-ylidene)methyl)-2-methyl-1H-pyrrole-3carboxamide (14c). Yellow solid; Yield: $0.7 \mathrm{~g}$ (33\%); m.p. 230.5-232.0 ${ }^{\circ} \mathrm{C}$; ${ }^{1} \mathrm{H}-\mathrm{NMR}$ (DMSO- $d_{6}$ ): $\delta 1.23$ (s, 1H, NH), 2.47 (s, 3H, $\left.\mathrm{CH}_{3}\right), 3.99-4.13\left(\mathrm{~m}, 4 \mathrm{H}, \mathrm{CH}_{2} \times 2\right), 4.73-4.82(\mathrm{~m}, 1 \mathrm{H}, \mathrm{CH}), 6.84-8.26$ $(\mathrm{m}, 5 \mathrm{H}$, aromatic, vinyl, $\mathrm{CONH}), 10.95(\mathrm{~s}, 1 \mathrm{H}$, indolin-2-one $\mathrm{NH}), 13.75(\mathrm{~s}, 1 \mathrm{H}$, pyrrole $\mathrm{NH})$; ${ }^{13} \mathrm{C}-\mathrm{NMR}$ (DMSO- $\left.d_{6}\right): \delta$ 11.02, 42.07, 53.04, 107.21, 110.30, 114.08, 117.98, 119.76, 120.01, 124.45, 126.32, 127.01, 131.43, 135.55, 158.42, 164.07, 170.12; HRMS (ESI) $\mathrm{m} / \mathrm{z}(\mathrm{M}+\mathrm{H})^{+}$: calculated for $\mathrm{C}_{18} \mathrm{H}_{17} \mathrm{ClFN}_{4} \mathrm{O}_{2}^{+}: 375.1368$, found 375.1369 .

(Z)-4-Chloro-5-((5-fluoro-2-oxoindolin-3-ylidene)methyl)-2-methyl-N-propyl-1H-pyrrole-3-carboxamide (14d). Yellow solid; Yield: $1.0 \mathrm{~g}(43 \%)$; m.p. > $290{ }^{\circ} \mathrm{C}$; ${ }^{1} \mathrm{H}-\mathrm{NMR}$ (DMSO- $\left.d_{6}\right): \delta 0.92$ (t, $J=7.32 \mathrm{~Hz}$, $\left.3 \mathrm{H}, \mathrm{CH}_{3}\right), 1.49-1.58\left(\mathrm{~m}, 2 \mathrm{H}, \mathrm{CH}_{2}\right), 2.46\left(\mathrm{~s}, 3 \mathrm{H}, \mathrm{CH}_{3}\right), 3.18-3.23\left(\mathrm{~m}, 2 \mathrm{H}, \mathrm{CH}_{2}\right), 6.87-7.84(\mathrm{~m}, 5 \mathrm{H}$, aromatic, vinyl, $\mathrm{CONH}), 11.09(\mathrm{~s}, 1 \mathrm{H}$, indolin-2-one $\mathrm{NH}), 13.85(\mathrm{~s}, 1 \mathrm{H}$, pyrrole $\mathrm{NH}) ;{ }^{13} \mathrm{C}-\mathrm{NMR}$ (DMSO-d $)_{6}$ : $\delta 11.94,13.97,22.89,41.04,107.12,110.92,114.09,115.67,118.55,118.96,121.82$, $122.65,124.38,135.81,136.56,159.35,162.66,169.95$; HRMS $(\mathrm{ESI}) \mathrm{m} / z(\mathrm{M}+\mathrm{H})^{+}$: calculated for $\mathrm{C}_{18} \mathrm{H}_{18} \mathrm{ClFN}_{3} \mathrm{O}_{2}^{+}: 362.1072(\mathrm{M}+1)$, found 362.1073.

(Z)-4-Chloro-N-(3-(dimethylamino)propyl)-5-((5-fluoro-2-oxoindolin-3-ylidene)methyl)-2-methyl-1Hpyrrole-3-carboxamide (14e). Yellow solid; Yield: $1.1 \mathrm{~g}(45 \%)$; m.p. $235.1-237.3{ }^{\circ} \mathrm{C}$; ${ }^{1} \mathrm{H}-\mathrm{NMR}$ (DMSO-d $\left.)_{6}\right): \delta 0.87-0.91\left(\mathrm{~m}, 2 \mathrm{H}, \mathrm{CH}_{2}\right), 2.20\left(\mathrm{~s}, 6 \mathrm{H}, \mathrm{CH}_{3} \times 2\right), 2.41\left(\mathrm{t}, J=6.76 \mathrm{~Hz}, 2 \mathrm{H}, \mathrm{CH}_{2}\right), 2.49$ $\left(\mathrm{s}, 3 \mathrm{H}, \mathrm{CH}_{3}\right), 3.31-3.35\left(\mathrm{~m}, 2 \mathrm{H}, \mathrm{CH}_{2}\right), 6.87-7.75(\mathrm{~m}, 5 \mathrm{H}$, aromatic, vinyl, $\mathrm{CONH}), 11.10(\mathrm{~s}, 1 \mathrm{H}$, indolin-2-one $\mathrm{NH}$ ), $13.87\left(\mathrm{~s}, 1 \mathrm{H}\right.$, pyrrole $\mathrm{NH}$ ); ${ }^{13} \mathrm{C}-\mathrm{NMR}$ (DMSO- $\left.d_{6}\right): \delta 13.90,26.40,34.37,43.23$, 56.60, 107.35 110.08, 112.33, 113.49, 118.03, 120.29, 123.80, 124.67, 125.17, 133.72, 139.49, 157.27, 164.55, 168.66; HRMS (ESI) $\mathrm{m} / z(\mathrm{M}+\mathrm{H})^{+}$: calculated for $\mathrm{C}_{20} \mathrm{H}_{23} \mathrm{ClFN}_{4} \mathrm{O}_{2}{ }^{+}$: 405.1494, found 405.1491 .

(Z)-4-Chloro-N-(2-(dimethylamino)ethyl)-5-((5-fluoro-2-oxoindolin-3-ylidene)methyl)-2-methyl-1Hpyrrole-3-carboxamide (14f). Yellow solid; Yield: 1.0 g $(42 \%)$; m.p. $271.8-274.2{ }^{\circ} \mathrm{C}$; ${ }^{1} \mathrm{H}-\mathrm{NMR}$ $\left(\mathrm{DMSO}-d_{6}\right): \delta 2.21\left(\mathrm{~s}, 6 \mathrm{H}, \mathrm{CH}_{3} \times 2\right), 2.41\left(\mathrm{t}, J=6.76 \mathrm{~Hz}, 2 \mathrm{H}, \mathrm{CH}_{2}\right), 2.49\left(\mathrm{~s}, 3 \mathrm{H}, \mathrm{CH}_{3}\right), 3.32(\mathrm{q}, J=6.76 \mathrm{~Hz}$, $\left.2 \mathrm{H}, \mathrm{CH}_{2}\right), 6.87-7.75(\mathrm{~m}, 5 \mathrm{H}$, aromatic, vinyl, $\mathrm{CONH}), 11.09$ (s, 1H, indolin-2-one $\left.\mathrm{NH}\right), 13.87$ (s, 1H, pyrrole NH); ${ }^{13} \mathrm{C}-\mathrm{NMR}$ (DMSO- $\left.d_{6}\right): \delta 13.91,34.42,43.25,56.66,110.20,112.47,113.33,115.58$, $118.02,118.13,120.50,123.89,125.39,133.81,139.53,157.34,164.70,168.81$; HRMS (ESI) $\mathrm{m} / \mathrm{z}$ $(\mathrm{M}+\mathrm{H})^{+}$: calculated for $\mathrm{C}_{19} \mathrm{H}_{21} \mathrm{ClFN}_{4} \mathrm{O}_{2}^{+}:$391.1337, found 391.1338 .

(Z)-4-Chloro-N-(2-(ethylamino)ethyl)-5-((5-fluoro-2-oxoindolin-3-ylidene)methyl)-2-methyl-1H-pyrrole3-carboxamide (14g). Yellow solid; Yield: 0.8 g (33\%); m.p. 211.0-211.8 ${ }^{\circ} \mathrm{C}$; ${ }^{1} \mathrm{H}-\mathrm{NMR}$ (DMSO- $d_{6}$ ): $\delta 1.04\left(\mathrm{t}, J=7.13 \mathrm{~Hz}, 3 \mathrm{H}, \mathrm{CH}_{3}\right), 1.21(\mathrm{~s}, 1 \mathrm{H}, \mathrm{NH}), 2.48\left(\mathrm{~s}, 3 \mathrm{H}, \mathrm{CH}_{3}\right), 2.61\left(\mathrm{q}, J=7.13 \mathrm{~Hz}, 2 \mathrm{H}, \mathrm{CH}_{2}\right)$, 
$2.72\left(\mathrm{t}, J=7.13 \mathrm{~Hz}, 2 \mathrm{H}, \mathrm{CH}_{2}\right), 3.32\left(\mathrm{q}, J=7.13 \mathrm{~Hz}, 2 \mathrm{H}, \mathrm{CH}_{2}\right), 6.87-7.94$ (m, 5H, aromatic, vinyl, $\mathrm{CONH}$ ), 11.27 (s, $1 \mathrm{H}$, indolin-2-one $\mathrm{NH}), 13.87$ (s, $1 \mathrm{H}$, pyrrole $\mathrm{NH}$ ); ${ }^{13} \mathrm{C}-\mathrm{NMR}$ (DMSO- $d_{6}$ ): $\delta$ 14.12, 15.31, 38.21, 43.51, 48.52, 107.02, 111.05, 114.15, 118.30, 118.78, 122.60, 124.43, 125.96, 126.63, 135.86, 137.11, 158.84, 162.76, 169.95; HRMS (ESI) $\mathrm{m} / \mathrm{z}(\mathrm{M}+\mathrm{H})^{+}$: calculated for $\mathrm{C}_{19} \mathrm{H}_{21} \mathrm{ClFN}_{4} \mathrm{O}_{2}^{+}: 391.1337$, found 391.1340.

(Z)-4-Chloro-N-(2-(diethylamino)ethyl)-5-((5-fluoro-2-oxoindolin-3-ylidene $)$ methyl)-2-methyl-1Hpyrrole-3-carboxamide (14h). Yellow solid; Yield: 1.1 g (44\%); m.p. $245.6-246.9{ }^{\circ} \mathrm{C}$; ${ }^{1} \mathrm{H}-\mathrm{NMR}$ $\left(\mathrm{DMSO}-d_{6}\right): \delta 1.19\left(\mathrm{t}, J=7.12 \mathrm{~Hz}, 6 \mathrm{H}, \mathrm{CH}_{3} \times 2\right), 2.39\left(\mathrm{~s}, 3 \mathrm{H}, \mathrm{CH}_{3}\right), 2.69-2.77\left(\mathrm{~m}, 6 \mathrm{H}, \mathrm{CH}_{2} \times 3\right)$, 3.31-3.43 (m, 2H, $\left.\mathrm{CH}_{2}\right), 6.78-7.77$ (m, 5H, aromatic, vinyl, $\left.\mathrm{CONH}\right), 11.07$ (s, 1H, indolin-2-one $\left.\mathrm{NH}\right)$, 14.12 (s, $1 \mathrm{H}$, pyrrole NH); ${ }^{13} \mathrm{C}-\mathrm{NMR}$ (DMSO- $d_{6}$ ): $\delta 8.42,13.83,34.21,48.21,50.52,107.26,109.98$, 112.24, 117.99, 120.05, 120.19, 123.76, 124.97, 125.24, 133.66, 139.35, 156.86, 164.52, 168.55; HRMS (ESI) $m / z(\mathrm{M}+\mathrm{H})^{+}$: calculated for $\mathrm{C}_{21} \mathrm{H}_{25} \mathrm{ClFN}_{4} \mathrm{O}_{2}{ }^{+}: 419.1650$, found 419.1653 .

(Z)-4-Chloro-5-((5-chloro-2-oxoindolin-3-ylidene)methyl)-N-(2-(diethylamino)ethyl)-2-methyl-1Hpyrrole-3-carboxamide (14i). Yellow solid; Yield: $1.1 \mathrm{~g}$ (40\%); m.p. 246.0-247.0 ${ }^{\circ} \mathrm{C}$; ${ }^{1} \mathrm{H}-\mathrm{NMR}$ $\left(\mathrm{DMSO}-d_{6}\right): \delta 1.14\left(\mathrm{t}, J=7.26 \mathrm{~Hz}, 6 \mathrm{H}, \mathrm{CH}_{3} \times 2\right), 2.45\left(\mathrm{~s}, 3 \mathrm{H}, \mathrm{CH}_{3}\right), 2.62-2.72\left(\mathrm{~m}, 6 \mathrm{H}, \mathrm{CH}_{2} \times 3\right)$, 3.46-3.48 (m, 2H, $\left.\mathrm{CH}_{2}\right), 6.67-7.65$ (m, 5H, aromatic, vinyl, $\left.\mathrm{CONH}\right), 11.14$ (s, 1H, indolin-2-one $\left.\mathrm{NH}\right)$, 14.19 (s, $1 \mathrm{H}$, pyrrole NH); ${ }^{13} \mathrm{C}-\mathrm{NMR}$ (DMSO- $d_{6}$ ): $\delta 8.51,14.04,34.44,48.31,50.73,113.28,117.30$, 117.77, 118.27, 120.34, 123.86, 125.44, 126.45, 126.47, 126.54, 136.06, 139.58, 164.81, 168.48; HRMS (ESI) $m / z(\mathrm{M}+\mathrm{H})^{+}$: calculated for $\mathrm{C}_{21} \mathrm{H}_{25} \mathrm{Cl}_{2} \mathrm{~N}_{4} \mathrm{O}_{2}{ }^{+}: 435.1355$, found 435.1354 .

(Z)-5-((5-bromo-2-oxoindolin-3-ylidene)methyl)-2-chloro- $N$-(2-(diethylamino $)$ ethyl)-4-methyl-1Hpyrrole-3-carboxamide (14j). Yellow solid; Yield: $1.2 \mathrm{~g}(39 \%)$; m.p. $248.1-248.5{ }^{\circ} \mathrm{C}$; ${ }^{1} \mathrm{H}-\mathrm{NMR}$ $\left(\mathrm{DMSO}-d_{6}\right): \delta 1.01\left(\mathrm{t}, J=7.10 \mathrm{~Hz}, 6 \mathrm{H}, \mathrm{CH}_{3} \times 2\right), 2.24\left(\mathrm{~s}, 3 \mathrm{H}, \mathrm{CH}_{3}\right), 2.61-2.68\left(\mathrm{~m}, 6 \mathrm{H}, \mathrm{CH}_{2} \times 3\right)$, 3.46-3.50 (m, 2H, $\left.\mathrm{CH}_{2}\right), 6.78-7.76(\mathrm{~m}, 5 \mathrm{H}$, aromatic, vinyl, $\mathrm{CONH}), 10.85$ (s, 1H, indolin-2-one $\left.\mathrm{NH}\right)$, 13.53 (s, $1 \mathrm{H}$, pyrrole NH); ${ }^{13} \mathrm{C}-\mathrm{NMR}$ (DMSO- $d_{6}$ ): $\delta 8.66,13.94,36.14,50.31,52.70,113.26,116.87$, 117.27, 119.07, 121.15, 123.54, 125.24, 126.05, 126.49, 126.54, 136.06, 139.24, 162.56, 168.98; HRMS (ESI) $\mathrm{m} / \mathrm{z}(\mathrm{M}+\mathrm{H})^{+}$: calculated for $\mathrm{C}_{21} \mathrm{H}_{24} \mathrm{BrClN}_{4} \mathrm{O}_{2}$ and $\mathrm{C}_{21} \mathrm{H}_{26} \mathrm{Cl}_{2} \mathrm{~N}_{4} \mathrm{O}_{2}{ }^{2+}: 478.0771$ (M), 480.0742 (M+2), found 478.0773, 480.0743.

(Z)-4-Chloro-N-(2-(diethylamino)ethyl)-2-methyl-5-((2-oxoindolin-3-ylidene $)$ methyl)-1H-pyrrole-3carboxamide (14k). Yellow solid; Yield: $1.1 \mathrm{~g}(43 \%)$; m.p. 238.5-240.1 ${ }^{\circ} \mathrm{C}$; ${ }^{1} \mathrm{H}-\mathrm{NMR}$ (DMSO- $d_{6}$ ): $\delta 1.01\left(\mathrm{t}, J=7.25 \mathrm{~Hz}, 6 \mathrm{H}, \mathrm{CH}_{3} \times 2\right), 2.43\left(\mathrm{~s}, 3 \mathrm{H}, \mathrm{CH}_{3}\right), 2.52-2.57\left(\mathrm{~m}, 6 \mathrm{H}, \mathrm{CH}_{2} \times 3\right), 3.32-3.36(\mathrm{~m}, 2 \mathrm{H}$, $\left.\mathrm{CH}_{2}\right), 6.91-7.74(\mathrm{~m}, 6 \mathrm{H}$, aromatic, vinyl, $\mathrm{CONH}), 11.10(\mathrm{~s}, 1 \mathrm{H}$, indolin-2-one $\mathrm{NH}), 13.82(\mathrm{~s}, 1 \mathrm{H}$, pyrrole NH); ${ }^{13} \mathrm{C}-\mathrm{NMR}$ (DMSO- $d_{6}$ ): $\delta 8.45,13.92,34.37,48.25,50.70,109.53,112.17,117.30$, 118.24, 118.57, 119.42, 121.83, 124.12, 127.28, 136.62, 137.81, 138.93, 165.02, 168.83; HRMS (ESI) $\mathrm{m} / \mathrm{z}(\mathrm{M}+\mathrm{H})^{+}$: calculated for $\mathrm{C}_{21} \mathrm{H}_{26} \mathrm{ClN}_{4} \mathrm{O}_{2}^{+}:$401.1744, found 401.1741 .

(Z)-4-Chloro-N-(2-(diethylamino)ethyl)-2-methyl-5-((5-methyl-2-oxoindolin-3-ylidene)methyl)-1Hpyrrole-3-carboxamide (14l). Yellow solid; Yield: $1.0 \mathrm{~g}(40 \%)$; m.p. $238.2-240.0{ }^{\circ} \mathrm{C}$; ${ }^{1} \mathrm{H}-\mathrm{NMR}$ (DMSO-d $)_{6}$ ): $\delta 0.99$ (t, $\left.J=7.09 \mathrm{~Hz}, 6 \mathrm{H}, \mathrm{CH}_{3} \times 2\right), 2.31\left(\mathrm{~s}, 3 \mathrm{H}, \mathrm{CH}_{3}\right), 2.50\left(\mathrm{~s}, 3 \mathrm{H}, \mathrm{CH}_{3}\right), 2.53-2.59(\mathrm{~m}, 6 \mathrm{H}$, $\left.\mathrm{CH}_{2} \times 3\right), 3.39-3.43$ (m, 2H, $\mathrm{CH}_{2}$ ), 6.79-7.64 (m, 5H, aromatic, vinyl, $\mathrm{CONH}$ ), 10.98 (s, 1H, indolin-2-one 
$\mathrm{NH}), 13.82\left(\mathrm{~s}, 1 \mathrm{H}\right.$, pyrrole NH); ${ }^{13} \mathrm{C}-\mathrm{NMR}\left(\mathrm{DMSO}-d_{6}\right): \delta 8.46,13.89,20.36,34.41,48.29,50.81$, $109.11,112.05,116.91,118.57,118.91,119.01,124.15,127.71,131.24,135.58,135.76,138.68$, 165.25, 168.88; HRMS (ESI) $m / z(\mathrm{M}+\mathrm{H})^{+}$: calculated for $\mathrm{C}_{22} \mathrm{H}_{28} \mathrm{ClN}_{4} \mathrm{O}_{2}{ }^{+}:$415.1901, found 415.1903.

(Z)-2,4-Dichloro-N-(2-(diethylamino)ethyl)-5-((5-fluoro-2-oxoindolin-3-ylidene)methyl)-1H-pyrrole-3carboxamide (14m). Yellow solid; Yield: $1.1 \mathrm{~g}$ (42\%); m.p. 269.1-270.3 ${ }^{\circ} \mathrm{C}$; ${ }^{1} \mathrm{H}-\mathrm{NMR}$ (DMSO- $d_{6}$ ): $\delta 1.03\left(\mathrm{t}, J=7.17 \mathrm{~Hz}, 6 \mathrm{H}, \mathrm{CH}_{3} \times 2\right), 2.45-2.50\left(\mathrm{~m}, 6 \mathrm{H}, \mathrm{CH}_{3} \times 2\right), 3.25-3.30\left(\mathrm{~m}, 2 \mathrm{H}, \mathrm{CH}_{2}\right), 6.89-7.97$ $(\mathrm{m}, 5 \mathrm{H}$, aromatic, vinyl, $\mathrm{CONH}), 11.15(\mathrm{~s}, 1 \mathrm{H}$, indolin-2-one $\mathrm{NH}), 13.92(\mathrm{~s}, 1 \mathrm{H}$, pyrrole $\mathrm{NH})$; ${ }^{13} \mathrm{C}-\mathrm{NMR}\left(\mathrm{DMSO}-d_{6}\right.$ ): $\delta 12.45,35.15,48.60,55.12,109.25,112.34,115.55,118.03,119.04,120.11$, 122.31, 126.36, 127.40, 128.11, 134.88, 158.57, 162.27, 169.66; HRMS (ESI) $m / z(\mathrm{M}+\mathrm{H})^{+}:$calculated for $\mathrm{C}_{20} \mathrm{H}_{22} \mathrm{Cl}_{2} \mathrm{FN}_{4} \mathrm{O}_{2}^{+}$: 439.1027, found 439.1024.

(Z)-2-Chloro-N-(2-(diethylamino)ethyl)-5-((5-fluoro-2-oxoindolin-3-ylidene)methyl)-1H-pyrrole-3carboxamide (14n). Yellow solid; Yield: 1.0 g (39\%); m.p. $233.5-234.7{ }^{\circ} \mathrm{C} ;{ }^{1} \mathrm{H}-\mathrm{NMR}$ (DMSO- $\left.d_{6}\right): \delta 0.98$ $\left(\mathrm{t}, J=7.16 \mathrm{~Hz}, 6 \mathrm{H}, 2 \times \mathrm{CH}_{3}\right), 2.51-2.56\left(\mathrm{~m}, 6 \mathrm{H}, 3 \times \mathrm{CH}_{2}\right), 3.25-3.30\left(\mathrm{~m}, 2 \mathrm{H}, \mathrm{CH}_{2}\right), 6.88-8.00(\mathrm{~m}, 6 \mathrm{H}$, aromatic, vinyl, CONH, pyrrole), 11.17 (s, 1H, indolin-2-one $\mathrm{NH}), 14.32$ (s, 1H, pyrrole $\mathrm{NH}$ ); ${ }^{13} \mathrm{C}-\mathrm{NMR}$ (DMSO- $d_{6}$ ): $\delta$ 12.37, 37.40, 47.21, 51.92, 107.15, 111.25, 114.55, 118.53, 119.64, 120.02, 121.39, 126.50, 127.37, 128.11, 135.96, 158.78, 161.77, 169.98; HRMS (ESI) $m / z(M+H)^{+}:$calculated for $\mathrm{C}_{20} \mathrm{H}_{23} \mathrm{ClFN}_{4} \mathrm{O}_{2}^{+}$: 405.1494, found 405.1497.

(Z)-2-Chloro-N-(2-(diethylamino)ethyl)-5-((5-fluoro-2-oxoindolin-3-ylidene)methyl)-4-methyl-1Hpyrrole-3-carboxamide (14o). Yellow solid; Yield: 1.0 g $(41 \%)$; m.p. $243.4-244.0{ }^{\circ} \mathrm{C}$; ${ }^{1} \mathrm{H}-\mathrm{NMR}$ (DMSO- $d_{6}$ ): $\delta 0.99$ (t, $\left.J=7.05 \mathrm{~Hz}, 6 \mathrm{H}, \mathrm{CH}_{3} \times 2\right), 2.44\left(\mathrm{~s}, 3 \mathrm{H}, \mathrm{CH}_{3}\right), 2.60-2.70\left(\mathrm{~m}, 6 \mathrm{H}, \mathrm{CH}_{2} \times 3\right)$, 3.51-3.55 (m, 2H, $\left.\mathrm{CH}_{2}\right), 6.87-7.86(\mathrm{~m}, 5 \mathrm{H}$, aromatic, vinyl, $\mathrm{CONH}), 11.15$ (s, 1H, indolin-2-one $\left.\mathrm{NH}\right)$, 14.53 (s, $1 \mathrm{H}$, pyrrole NH); ${ }^{13} \mathrm{C}-\mathrm{NMR}$ (DMSO- $\left.d_{6}\right): \delta 11.01,12.36,37.55,47.02,51.92,107.16,110.92$, 113.92, 117.92, 119.64, 119.75, 125.11, 126.73, 127.01, 130.49, 135.42, 158.82, 162.68, 170.22; HRMS (ESI) $m / z(\mathrm{M}+\mathrm{H})^{+}$: calculated for $\mathrm{C}_{21} \mathrm{H}_{25} \mathrm{ClFN}_{4} \mathrm{O}_{2}{ }^{+}: 419.1650$, found 419.1652 .

(Z)-2-Chloro-N-(2-(ethylamino)ethyl)-5-((5-fluoro-2-oxoindolin-3-ylidene)methyl)-4-methyl-1H-pyrrole3-carboxamide (14p). Yellow solid; Yield: $0.8 \mathrm{~g}$ (34\%); m.p. 215.0-216.8 ${ }^{\circ} \mathrm{C} ;{ }^{1} \mathrm{H}-\mathrm{NMR}$ (DMSO- $\left.d_{6}\right): \delta$ $1.03\left(\mathrm{t}, J=7.13 \mathrm{~Hz}, 3 \mathrm{H}, \mathrm{CH}_{3}\right), 1.23(\mathrm{~s}, 1 \mathrm{H}, \mathrm{NH}), 2.43\left(\mathrm{~s}, 3 \mathrm{H}, \mathrm{CH}_{3}\right), 2.60$ (q, J = 7.13 Hz, 2H, $\mathrm{CH}_{2}$ ), $2.70\left(\mathrm{t}, J=7.13 \mathrm{~Hz}, 2 \mathrm{H}, \mathrm{CH}_{2}\right), 3.32\left(\mathrm{q}, J=7.13 \mathrm{~Hz}, 2 \mathrm{H}, \mathrm{CH}_{2}\right), 6.87-7.89$ (m, 5H, aromatic, vinyl, CONH), 11.27 (s, 1H, indolin-2-one $\mathrm{NH}), 14.50\left(\mathrm{~s}, 1 \mathrm{H}\right.$, pyrrole $\mathrm{NH}$ ); ${ }^{13} \mathrm{C}-\mathrm{NMR}$ (DMSO- $\left.d_{6}\right)$ : $\delta 10.97,14.36,38.37,43.30,48.06,107.31,110.96,113.98,118.01,119.62,119.90,125.11,126.76$, 127.08, 130.45, 135.46, 157.67, 163.06, 170.23; HRMS (ESI) $m / z(M+H)^{+}$: calculated for $\mathrm{C}_{19} \mathrm{H}_{21} \mathrm{ClFN}_{4} \mathrm{O}_{2}^{+}:$391.1337, found 391.1335.

(Z)-2-Chloro-N-(2-(diethylamino)ethyl)-4-ethyl-5-((5-fluoro-2-oxoindolin-3-ylidene)methyl)-1H-pyrrole3-carboxamide (14q). Yellow solid; Yield: 1.2 g (45\%); m.p. 245.2-246.8 ${ }^{\circ} \mathrm{C}$; ${ }^{1} \mathrm{H}-\mathrm{NMR}$ (DMSO- $d_{6}$ ): $\delta 0.98\left(\mathrm{t}, J=7.09 \mathrm{~Hz}, 6 \mathrm{H}, \mathrm{CH}_{3} \times 2\right), 1.12\left(\mathrm{t}, J=7.09 \mathrm{~Hz}, 3 \mathrm{H}, \mathrm{CH}_{3}\right), 2.44-2.62\left(\mathrm{~m}, 6 \mathrm{H}, \mathrm{CH}_{2} \times 3\right), 2.92$ (q, $\left.J=7.09 \mathrm{~Hz}, 2 \mathrm{H}, \mathrm{CH}_{2}\right), 3.29-3.35\left(\mathrm{~m}, 2 \mathrm{H}, \mathrm{CH}_{2}\right), 6.88-7.89$ (m, 5H, aromatic, vinyl, $\left.\mathrm{CONH}\right), 11.14$ (s, 1H, indolin-2-one NH), $14.51\left(\mathrm{~s}, 1 \mathrm{H}\right.$, pyrrole NH); ${ }^{13} \mathrm{C}-\mathrm{NMR}$ (DMSO- $\left.d_{6}\right): \delta 12.31,17.29,17.97$, 37.53 , 46.99, 51.93, 107.27, 110.93, 113.93, 118.08, 124.85, 125.93, 126.96, 127.06, 135.42, 137.26, 
158.84, 162.82, 170.19; HRMS (ESI) $m / z(\mathrm{M}+\mathrm{H})^{+}$: calculated for $\mathrm{C}_{22} \mathrm{H}_{27} \mathrm{ClFN}_{4} \mathrm{O}_{2}{ }^{+}$: 433.1807, found 433.1809.

(Z)-2-Chloro-4-ethyl-N-(2-(ethylamino)ethyl)-5-((5-fluoro-2-oxoindolin-3-ylidene $)$ methyl)-1H-pyrrole3-carboxamide (14r). Yellow solid; Yield: 0.9 g (36\%); m.p. 232.0-233.1 ${ }^{\circ} \mathrm{C}$; ${ }^{1} \mathrm{H}-\mathrm{NMR}$ (DMSO- $d_{6}$ ): $\delta$ 1.07-1.14 (m, 6H, $\left.\mathrm{CH}_{3} \times 2\right), 1.22(\mathrm{~s}, 1 \mathrm{H}, \mathrm{NH}), 2.71\left(\mathrm{q}, J=7.15 \mathrm{~Hz}, 2 \mathrm{H}, \mathrm{CH}_{2}\right), 2.80$ (t, $J=7.15 \mathrm{~Hz}$, $\left.2 \mathrm{H}, \mathrm{CH}_{2}\right), 2.93\left(\mathrm{q}, J=7.15 \mathrm{~Hz}, 2 \mathrm{H}, \mathrm{CH}_{2}\right), 3.44\left(\mathrm{q}, J=7.15 \mathrm{~Hz}, 2 \mathrm{H}, \mathrm{CH}_{2}\right), 6.88-8.10(\mathrm{~m}, 5 \mathrm{H}$, aromatic, vinyl, CONH), $11.20\left(\mathrm{~s}, 1 \mathrm{H}\right.$, indolin-2-one $\mathrm{NH}$ ), $14.58(\mathrm{~s}, 1 \mathrm{H}$, pyrrole $\mathrm{NH}) ;{ }^{13} \mathrm{C}-\mathrm{NMR}$ (DMSO- $\left.d_{6}\right)$ : $\delta$ 13.75, 17.26, 17.98, 37.87, 43.08, 47.57, 107.29, 110.98, 113.96, 118.19, 119.07, 119.57, 124.83, 125.96, 126.98, 135.48, 137.23, 158.84, 163.23, 170.18; HRMS (ESI) $\mathrm{m} / \mathrm{z}(\mathrm{M}+\mathrm{H})^{+}$: calculated for $\mathrm{C}_{20} \mathrm{H}_{23} \mathrm{ClFN}_{4} \mathrm{O}_{2}^{+}:$405.1494, found 405.1497.

\subsection{Cell Culture}

Non-small cell lung cancer (A549), oral epithelial (KB), large cell lung cancer (NCI-H460) and melanoma cell lines (K111) were cultured in Dulbecco's modified Eagle medium (GIBCO) containing $10 \%$ (v/v) inactivated newborn calf serum (Boren Bio-Pharmaceutical Co., Ltd.: Guangzhou, China), $1 \mathrm{nM}$ L-glutamine (SANGON), 105 units $/ \mathrm{mL}$ penicillin, $100 \mu \mathrm{g} / \mathrm{mL}$ streptomycin. Cells were grown in a $5 \%$ $\mathrm{CO}_{2}$ incubator at $37^{\circ} \mathrm{C}$.

\subsection{Cell Growth Inhibition Assay}

The antitumor activities were determined by the MTT assay. Cells $\left(2 \times 10^{3}\right.$ cells/well $)$ were seeded in 96-well plates. After incubation overnight, each compound, which was dissolved in dimethylsulfoxide (DMSO) and diluted with phosphate buffer solution (PBS), was added to each well and the cells were cultured for another two days at $37^{\circ} \mathrm{C} .20 \mu \mathrm{L}(5 \mathrm{mg} / \mathrm{mL})$ MTT solution was added to per well and the culture continued for another 3-4 h. The medium was removed and $100 \mu \mathrm{L}$ DMSO was added to dissolve formazan crystals. Absorbance was measured at $492 \mathrm{~nm}$ using an ELISA reader (Thermo). The antitumor activities were expressed as $\mathrm{IC}_{50}$.

\subsection{VEGFR2 Inhibition Assay}

The VEGFR2 inhibition assay was performed by enzyme-linked immunosorbent assay (ELISA) in 96-well plates pre-coated with $2.5 \mu \mathrm{g} /$ well Poly (Glu, Tyr) 4:1 $_{1}$ as a substrate. Each well was treated with $90 \mu \mathrm{L}$ of $5.0 \mu \mathrm{M}$ ATP (Amresco) solution and $10 \mu \mathrm{L}$ of one of the seven compounds at varying concentrations, which were diluted in reaction buffer (50 mM HEPES pH 7.4, $20 \mathrm{mM} \mathrm{MgCl} 2,0.1 \mathrm{mM}$ $\mathrm{Na}_{3} \mathrm{VO}_{4}, 1 \mathrm{mM}$ DTT). The known VEGFR2 inhibitor, Su11248 (sunitinib), was used as a positive control, and $0.1 \%(\mathrm{v} / \mathrm{v})$ DMSO was utilized as the negative control. The reaction was initiated by adding $1 \mu \mathrm{L} /$ well of VEGFR2 tyrosine kinase. After incubation for $1 \mathrm{~h}$ at $37{ }^{\circ} \mathrm{C}$, the plates were washed three times with phosphate buffered saline containing $0.1 \%$ Tween-20 (T-PBS). Next, anti-phosphotyrosine (PY99; 1:1,000 dilution, $100 \mu \mathrm{L} /$ well) antibody was added. After $1 \mathrm{~h}$ incubation at room temperature, the plates were washed three times, and goat anti-mouse IgG horseradish peroxidase (100 $\mu \mathrm{L} /$ well of 1:2,000 dilution) diluted in T-PBS was added. The plates were reincubated at room temperature for $1 \mathrm{~h}$, and washed as before. Finally, color development solution $\left(0.03 \% \mathrm{H}_{2} \mathrm{O}_{2}\right.$ and 


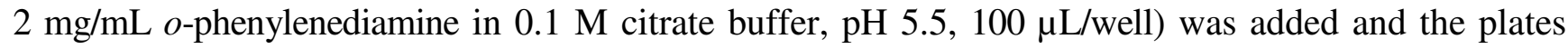
were incubated at room temperature until color emerged. The reaction was terminated by the addition of $2 \mathrm{M} \mathrm{H}_{2} \mathrm{SO}_{4}(50 \mu \mathrm{L} /$ well $)$, and $\mathrm{A}_{492}$ was measured using a tunable wavelength microplate reader (Molecular Devices SPECTRAMAX190). The inhibition rate was calculated using the equation: $\left[1-\left(\mathrm{A}_{492} / \mathrm{A}_{492}\right.\right.$ control $\left.)\right] \times 100 \%$.

\section{Conclusions}

In summary, we have prepared eighteen novel 3-substituted-indolin-2-one derivatives containing different $\mathrm{N}$-substituted-chloropyrroloformamides, and evaluated their biological activities. The antitumor activities were affected by the $\mathrm{N}$-substituents in the amides. Compounds 14c, 14f, 14g, 14h, 14i, 14p and 14r exhibited potent antitumor activities against the four tested tumor cell lines. Compound $\mathbf{1 4 g}$ showed the best inhibition against VEGFR2. Compounds $\mathbf{1 4 g}$ and $\mathbf{1 4 h}$, with a chloro group attached to the pyrrole moiety, showed low cardiotoxicity. Further experiments for the eighteen derivatives would be required for evaluating the inhibition activities against other RTKs VEGFR3, PDGFR $\beta$ and FGFR1 to conclude a comprehensive structure-activity relationship.

\section{Acknowledgments}

Financial support was provided by Fund of Science and Technology Development, Shanghai, China (No. 054319907 and No. 09431901400).

\section{References and Notes}

1. Ellis, L.M.; Fidler, I.J. Angiogenesis and metastasis. Eur. J. Cancer 1996, 32A, 2451-2460.

2. Carmeliet, P.; Jain, R.K. Angiogenesis in cancer and other diseases. Nature 2000, 407, 249-257.

3. Ferrara, N. VEGF and the quest for tumor angiogenesis factors. Nat. Rev. Cancer 2002, 2, 795-803.

4. Manley, P.W.; Martiny-Baron, G.; Schlaeppi, J.M.; Wood, J.M. Therapies directed at vascular endothelial growth factor. Expert Opin. Invest. Drugs 2002, 11, 1715-1736.

5. Schenone, S.; Bondavalli, F.; Botta, M. Antiangiogenic agents: An update on small molecular VEGFR inhibitors. Curr. Med. Chem. 2007, 14, 2495-2516.

6. Bhargava, P.; Robinson, M.O. Development of second-generation VEGFR tyrosine kinase inhibitors: Current status. Curr. Oncol. Rep. 2011, 13, 103-111.

7. Yancopoulos, G.D.; Davis, S.; Gale, N.W.; Rudge, J.S.; Wiegand, S.; Holash, J. Vascular-specific growth factors and blood vessel formation. Nature 2002, 407, 242.

8. Baindur, N.; Chadha, N.; Brandt, B.M.; Asgari, D.; Patch, R.J.; Schalk-HiHi, C.; Carver, T.E.; Petrounia, I.P.; Baumann, C.A.; Ott, H.; et al. 2-Hydroxy-4,6-diamino-[1,3,5]triazines: A novel class of VEGF-R2 (KDR) tyrosine kinase inhibitors. J. Med. Chem. 2005, 48, 1717-1720.

9. Peifer, C.; Krasowski, A.; Hämmerle, A.; Kohlbacher, O.; Dannhardt, G.; Totzke, F.; Schächtele, C.; Laufer, S. Profile and molecular modeling of 3-(indole-3-yl)-4-(3,4,5-trimethoxyphenyl)-1Hpyrrole-2,5-dione(I) as a highly selective VEGF-R2/3 inhibitor. J. Med. Chem. 2006, 49, 7549-7553. 
10. Weiss, M.M.; Harmange, J.; Polverino, A.J.; Bauer, D.; Berry, L.; Berry, V.; Borg, G.; Bready, J.; Chen, D.L.; Choquette, D.; et al. Evaluation of a series of naphthamides as potent, orally active vascular endothelial growth factor receptor-2 tyrosine kinase inhibitors. J. Med. Chem. 2008, 51, 1668-1680.

11. Renhowe, P.A.; Pecchi, S.; Shafer, C.M.; Machajewski, T.D.; Jazan, E.M.; Taylor, C.; Antonios-McCrea, W.; McBride, C.M.; Frazier, K.; Wiesmann, M.; et al. Design, structureactivity relationships and in vivo characterization of 4-amino-3-benzimidazol-2-ones: A novel class of receptor tyrosine kinase inhibitors. J. Med. Chem. 2009, 52, 278-292.

12. Lv, K.; Wang, L.L.; Liu, M.L.; Zhou, X.B.; Fan, S.Y.; Liu, H.Y.; Zheng, Z.B.; Li, S. Synthesis and antitumor activity of 5-[1-(dimethylamino)propyl)-5-halogenated-2-oxoindolin-(3Z)-ylidene methyl]-2,4-dimethyl-1H-pyrrole-3-carboxamides. Bioorg. Med. Chem. Lett. 2011, 21, 3062-3065.

13. Uddin, M.I.; Thirumalairajan, S.; Crawfor, S.M.; Cameron, T.S.; Thompson, A.S. Improved synthetic route to C-ring ester-functionalized prodigiosenes. Synlett 2010, 17, 2561-2564.

14. Sun, L.; Tran, N.; Tang, F.; App, H.; Hirth, P.; McMahon, G.; Tang, C. Synthesis and biological evaluations of 3-substituted indolin-2-ones: A novel class of tyrosine kinase inhibitors that exhibit selectivity toward particular receptor tyrosine kinases. J. Med. Chem. 1998, 41, 2588-2603.

15. Sun, L.; Tran, N.; Liang, C.; Tang, F.; Rice, A.; Schreck, R.; Waltz, K.; Shawver, L.K.; McMahon, G.; Tang, C. Design, synthesis, and evaluations of substituted 3-[(3- or 4-carboxy ethylpyrrol-2-yl)methylid enyl]indolin-2-ones as inhibitors of VEGF, FGF, and PDGF receptor tyrosine kinases. J. Med. Chem. 1999, 42, 5120-5130.

16. Sun, L.; Liang, C.; Shirazian, S.; Zhou, Y.; Miller, T.; Cui, J.; Fukuda, J.Y.; Chu, J.Y.; Nematalla, A.; Wang, X.Y.; et al. Discovery of 5-[5-fluoro-2-oxo-1,2-dihydroindol-(3Z)-ylidenemethyl]-2,4dimethyl-1H-pyrrole-3-carboxylic acid (2-diethylaminoethyl)amide, a novel tyrosine kinase inhibitor targeting vascular endothelial and platelet-derived growth factor receptor tyrosine kinase. J. Med. Chem. 2003, 46, 1116-1119.

17. Tang, P.C.; Su, Y.D.; Feng, J.; Fu, J.H.; Yang, J.L.; Xiao, L.; Peng, J.H.; Li, Y.L.; Zhang, L.; $\mathrm{Hu}, \mathrm{B}$; et al. Novel potent orally active multitargeted receptor tyrosine kinase inhibitors: synthesis, structure-activity relationships, and antitumor activities of 2-indolinone derivatives. J. Med. Chem. 2010, 53, 8140-8149.

18. Khanwelkar, R.R.; Chen, G.S.; Wang, H.C.; Yu, C.W.; Huang, C.H.; Lee, O.; Chen, C.H. Synthesis and SAR of 6-arylureido-3-pyrrole-2-ylmethylideneindolin-2-one derivatives as potent receptor tyrosine kinase inhibitors. Bioorg. Med. Chem. 2010, 18, 4674-4686.

19. Buchini, S.; Buschiazzo, A.; Withers, S.G. A new generation of specific typonosoma cruzi transsialidase inhibitors. Angew. Chem. Int. Ed. 2008, 47, 2700-2703.

20. Leite, A.; Moreira, D.; Cardoso, M. Synthesis, cruzain docking, and in vitro studies of aryl-4oxothiazolylhydrazones against trypanosome cruzi. Chem. Med. Chem. 2009, 2, 1339-1345.

21. Gerebtzoff, G.; Li, B.X.; Frentzel, A.; Seelig, A. Halogenation of drugs enhances membrane binding and permeation. ChemBioChem 2004, 5, 674-684.

22. Siegal, G.; Ab, E.; Schultz, J. Intergration of fragment screening and library design. Drug Discov. Today 2007, 12, 1032-1039.

23. Hrib, N.J. The dopamine D4 receptor: A controversial therapeutic target. Drugs Future 2000, 25, 587-611. 
24. Malakhat, A.T.; Valentina, I.V.; Karl, A.W.; Jeffrey, G.; Bakhtiyor, F.R.; Mikhail, G.L.; Shukhrat, B.R.; Nasrulla, D.A. Structure-activity relationship investigations of leishmanicidal N-benzylcytisine derivatives. Chem. Biol. Drug Des. 2011, 78, 183-189.

25. Marzo, V.D.; Griffin, G.; Petrocellis, L.D.; Brandi, I.; Bisogno, T.; Williams, W.; Grier, M.C.; Kulasegram, S.; Mahadevan, A.; Razdan, R.K.; et al. A structure/activity relationship study on arvanil, an endocannabinoid and vanilloid hybrid. J. Pharmacol. Exp. Ther. 2002, 3, 984-991.

26. Mohammadi, M.; McMahon, G.; Sun, L.; Tang, C.; Hirth, P.; Yeh, B.K.; Hubbard, S.R.; Schlessinger, J. Structure of the tyrosine kinase domain of fibroblast growth factor receptor in complex with inhibitors. Science 1997, 276, 955-960.

27. Khakoo, A.Y.; Kassiotis, C.M.; Tannir, N.; Plana, J.C.; Halushka, M.; Bickford, C.; Trent, J.; Champion, J.C.; Durand, J.B.; Lenihan, D.J. Heart failure associated with Sunitinib malate. Cancer 2008, 112, 2500-2508.

Sample Availability: Samples of the compounds are available from the authors.

(C) 2011 by the authors; licensee MDPI, Basel, Switzerland. This article is an open access article distributed under the terms and conditions of the Creative Commons Attribution license (http://creativecommons.org/licenses/by/3.0/). 